\title{
GEOLOGIA E PETROLOGIA DA MINA DE OURO SCHRAMM (GASPAR - SC)
}

\author{
JOÃO CARLOS BIONDI ${ }_{(1)}$, NILTON D. FRANKE $(2)$, PAULO R. S. DE CARVALHO ${ }_{(2)}$ E SANDRO N.VILLANOVA
}

\begin{abstract}
The highlights of the Schramm gold mine are its position inside a high-angle shear zone and the association of gold with nickel, arsenic and cobalt sulfides in massive veins of siderite-ankerite (dolomite). The quartz-carbonate lodes are not sheared or deformed. They are hosted by gneisses and granulites with intense hypogenic alteration (carbonatization, cloritization, sericitization and silicification). Gold is found free or inside sulfides only in the carbonates lodes, with grades varying from 500 to $2,300 \mathrm{ppm}$. Together with the gold there is silver (150 to $300 \mathrm{ppm})$, arsenic $(0.15$ to $0.60 \%)$ and nickel (0.01 to $1.4 \%)$. The ore also presents $\mathrm{Zn}$ (250 to $1,600 \mathrm{ppm}), \mathrm{Pb}(100$ to $850 \mathrm{ppm})$ and $\mathrm{Co}$ (40 to $750 \mathrm{ppm})$. The amounts of Sb, Te, Se, W, Mo and Bi are very low. The quartz veins from the lodes show gold grades below I ppm and of $\mathrm{As}, \mathrm{Zn}, \mathrm{Pb}, \mathrm{Ni}, \mathrm{Cu}, \mathrm{Co}, \mathrm{Mo}, \mathrm{Te}$ and $\mathrm{Bi}$ between $\mathrm{I}$ and $50 \mathrm{ppm}$. Outside the mineralized zones the gold grades are below $50 \mathrm{ppb}$ and the other elements grades are greater than in mineralized zones, varying from 10 and $900 \mathrm{ppm}$. Rarely rocks with hypogenic alteration have gold and its presence in grades higher than $50 \mathrm{ppb}$ does not increase the grades of the other elements, that vary from I and $200 \mathrm{ppm}$.

The total amount of sulfide is about $0.5 \%$ of the rock volume. The sulfide paragenesis has galena (rare), chalcopyrite (little), arsenopyrite (very rare), sphalerite, nickel-cobaltiferous pyrite, pyrite, siegenite-violarite, millerite, gersdoffite, covelite and one unknown $\mathrm{Ni}$-Fe-Co sulfo-arseniate with formulae $(\mathrm{Co}, \mathrm{Fe}, \mathrm{Ni})_{7 g_{0} 0} \mathrm{As}_{90 \times x)} \mathrm{S}_{6(\mathrm{x})}$, optically similar to gersdorfite, but distinguished by its cream-gray color. The structural formulae calculation shows that gold contains $27.5 \%$ of silver and that siegenite is an iron-rich variety, transitional to violarite.

Keywords: Schramm mine (Gaspar, SC, Brazil). Shear zone with gold in siderite-ankerite veins. Sulphur-niquel- arsenic paragenesis.
\end{abstract}

RESUMO A mina Schramm destaca-se por estar em uma zona de cisalhamento de alto ângulo e ter ouro associado a uma paragênese com sulfetos de níquel, arsênio e cobalto contidos em veios maciços de siderita-ankerita (dolomita). Os veios de carbonatos e de quartzo não estão cisalhados nem deformados. O minério concentra-se em bolsôes constituidos por veios de carbonatos e de quartzo, em meio a granulitos $\mathrm{c}$ gnaisses intensamente carbonatados, cloritizados, sericitizados e silicificados,. O ouro ocorre com teores entre 500 e 2.300 ppm, livre ou junto a sulfetos, somente nos veios de carbonatos. Junto ao ouro concentram-se prata $(1,50$ a $300 \mathrm{ppm})$, arsênio $(0,15$ a $0,60 \%)$ e níquel $(0,01$ a $1,4 \%)$. Em menores proporções o minério tem Zn (250 a I600 ppm), Pb (100 a 850 ppm) e Co (40 a 750 ppm). Os teores de Sb, Te, Se, W, Mo e Bi são muito baixos, próximos ou menores que $10 \mathrm{ppm}$. Os veios de quartzo dos bolsões têm teores de ouro de até $1 \mathrm{ppm}$ e de $\mathrm{As}, \mathrm{Zn}, \mathrm{Pb}, \mathrm{Ni}, \mathrm{Cu}$, Co, Mo, Te, e Bi entre I e 50 ppm. Fora das regiões mineralizadas os teores de Au são menores que 50 ppb e os teores dos outros elementos são maiores que os da zona mineralizada, variando entre 10 e $900 \mathrm{ppm}$. Raramente as rochas encaixantes têm ouro e a presença do ouro não traz um aumento significativo nos teores dos outros elementos.

A quantidade total de sulfetos é de cerca de $0,5 \%$ da rocha, em volume. A paragênese sulfetada que acompanha o ouro é constituida por galena (rara), calcopirita (pouca), arsenopirita (muito rara), esfalerita, pirita níquel-cobaltífera, pirita, siegenita-violarita, millerita, gersdorfita, covelita

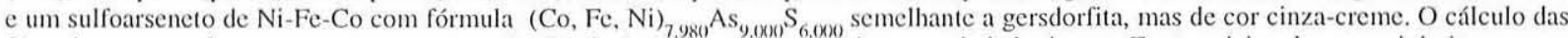
fórmulas estruturais mostrou que o ouro tem $27,5 \%$ de $\mathrm{Ag}$ e que a siegenita é uma variedade rica em Fe, transicional para a violarita.

Palavras chave: Mina Schramm (Gaspar, SC). Ouro em zona de cisalhamento em veios de siderita-ankerita. Paragênese sulfo-niquel-arseniada.

\begin{abstract}
INTRODUÇÃO E LOCALIZAÇĀO A mina de ouro Schramm está situada a $12 \mathrm{Km}$ a NNE de cidade de Gaspar (SC) (Fig. 1), na margem esquerda do ribeirão do Arraial. Em 1986 a MINEPAR - Mineração Gaspar S.A. - localizou 44 veios de quartzo na região. Dentre esses veios, 42 estão $\mathrm{em}$ meio a rochas do Grupo Itajaí e apenas dois, o Schramm c o Subida (Fig. 2), estão $\mathrm{em}$ meio a rochas do embasamento. A área foi abandonada e reativada várias vezes, até a descoberta, na área do Schramm, no final de 1999, de locais mineralizados com altos teores de ouro.
\end{abstract}

GEOLOGIA DA ÁREA Geologia regional Os veios dc quartzo mineralizados com ouro do Schramm ocorrem $\mathrm{cm}$ meio a rochas do Complexo Granulítico Luiz Alves, $\mathrm{em}$ uma zona de cisalhamento orientada $\mathrm{N} 5-10^{\circ} \mathrm{E}$, vertical, localizada muito próximo ao contato com as rochas do Grupo Itajaí (Fig. 1 e 2). Embora a maioria das rochas do Complexo sejam granulitos noríticos a enderbíticos $\mathrm{e}$ anfibolitos, são comuns as ocorrências de migmatitos estromáticos, gnaisses félsicos e/ou feldspáticos (rosados), quartzitos e formações ferríferas. Segundo Basei (1985), as rochas do Complexo Granulítico teriam uma idade mínima de $2,8 \mathrm{Ga}$.

As rochas metamórficas têm uma foliação regional com atitudes $\mathrm{cm}$ torno de $\mathrm{N} 30^{\circ} \mathrm{E}, 70-80^{\circ} \mathrm{NW}$ a SE. As zonas miloníticas têm direçōes

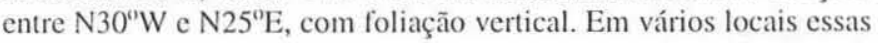
zonas foram reativadas em condições rúpteis. Segundo Babinski et al. (1997), a fase acrescional do cinturão Don Feliciano, a SE da Bacia do Itajaí, ocorreu entre $610 \pm 5$ e $616 \pm 2 \mathrm{Ma}$. A fase colisional, principal lase transcorrente que afetou a região, teria ocorrido há $594 \pm 5 \mathrm{Ma}$.

O Grupo Itajaí aflora como um conjunto de sedimentos detríticos, encimados e atravessados por riolitos e granitos. Está contido $\mathrm{em}$ uma bacia alongada (Fig. I) e limitada, na maior parte do seu perímetro, por falhas e zonas de cisalhamento que a separam do Complexo

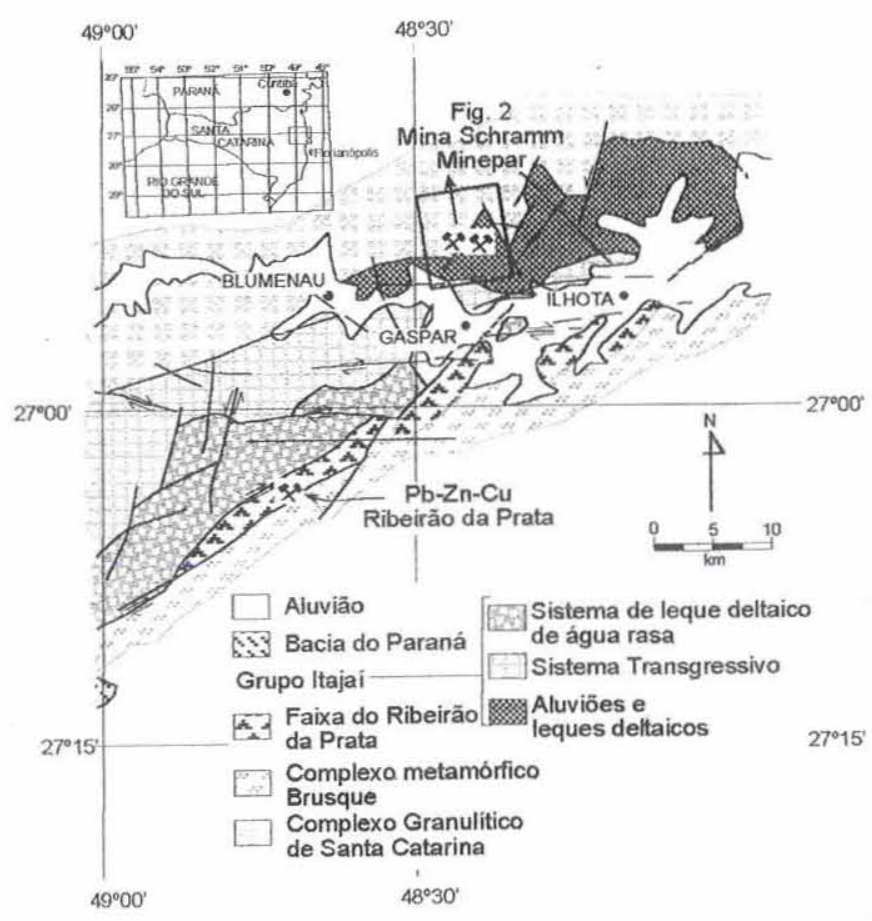

Fig. I: Localizasăo geográfica e geológica da mina de ouro Schramm (Biondi el (1l.. 1992) 
Granulítico. Suas rochas têm idades entre $580 \pm 40$ e $540 \pm 10$ Ma, c sofreram um anquimetamorfismo a $534 \pm 4 \mathrm{Ma}$ (Basei 1985). É possível, portanto, que a fase compressiva que deformou rochas do Grupo ltajaí tenha reativado as trancorrências neoproterozóicas.

Na região da mina Schramm afloram conglomerados polimíticos e arenitos feldspáticos com cores avermelhadas e amarronzadas. Estas rochas estão quase sempre horizontalizadas e, quando inclinadas, têm mergulhos de até $20^{\circ}$ para SSE. São recortadas por um sistema de fathas paralelas ENE (Fig. 2) que se prolongam no embasamento. As rochas sedimentares contêm muitas intrusões (apófises e diques) riodacíticas e riolíticas, geralmente orientadas paralelamente às falhas, Segundo Basei (1985), o magmatismo do Itajai cessou há $541 \pm 26 \mathrm{Ma}$. Os veios de quartzo mineralizados com ouro estão contidos nas falhas ENE, não raro junto a diques riodacíticos (Fig. 2).

Geologia da área da mina Schramm A mina Schramm (Fig. 3) lavra ouro em veios de siderita-ankerita e de quartzo (Fig. 4), orientados $\mathrm{N} 10^{\circ}-15^{\circ} \mathrm{W}, 80^{\circ}-85^{\circ} \mathrm{NE}$, alojados em uma zona de cisalhamento vertical NS (Fig. 2). As galerias atravessam rochas granulíticas básicas e ultrabásicas, muito foliadas e alteradas, que contêm lentes de gnaisses com larguras métricas. Há gnaisses félsicos (quartzosos), gnaisses róseos (ricos em feldspato potássico) e os "magnéticos", com bandas escuras de magnetita e hematita alternadas com bandas claras quartzo-feldspáticas. Todas as rochas estão carbonatadas (siderita, ankerita e dolomita). Os gnaisses estão silicificados e muscovitizados c os granulitos estão cloritizados e albitizados. A intensidade da alteração cresce em direção aos veios, tornando irreconhecíveis as texturas originais das rochas a distâncias menores que 1,0-1,5 metros dos contatos.

O corpo mineralizado é constituído por veios maciços de siderita c ankerita, com espessuras centimétricas a decimétricas e cores creme amarronadas, que ocorrem isolados (Fig. 4 A), margeando (Fig. 4 B, C e D) ou mesclados a veios, também maciços, de quartzo leitoso com aglomerados de carbonatos e de cloritas. Há um conjunto principal de veios, cuja largura varia entre 0,4 e 1,5 metros (Fig. 3 e 4), e um con-

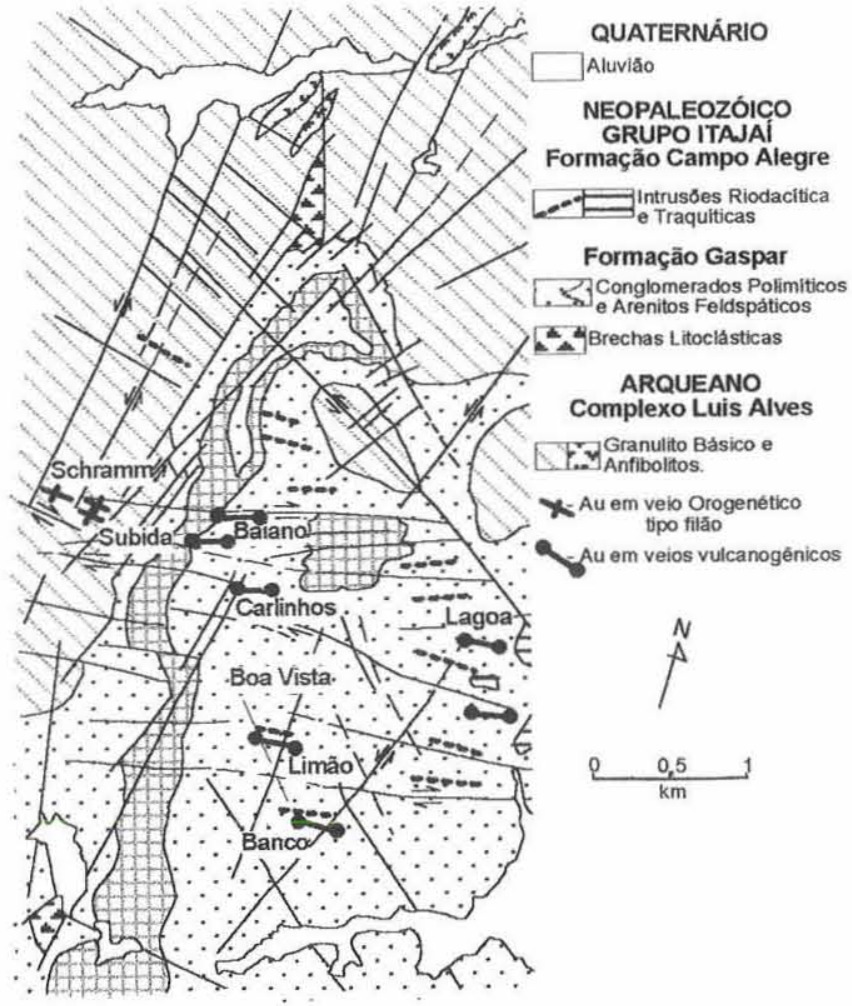

Fig. 2: Mapa geológico da regiāo da mina de ouro Schramm. A mina lavra reios de carbonato e quartzo orientados $N 10^{\circ}-15^{\circ} \mathrm{W}, 80^{\circ}-85^{\circ} \mathrm{NE}$ situados em uma zona de cisalhamento NS, muito próximo ao contato de rochas do Grupo Itajai (Biondi et al., 1992).

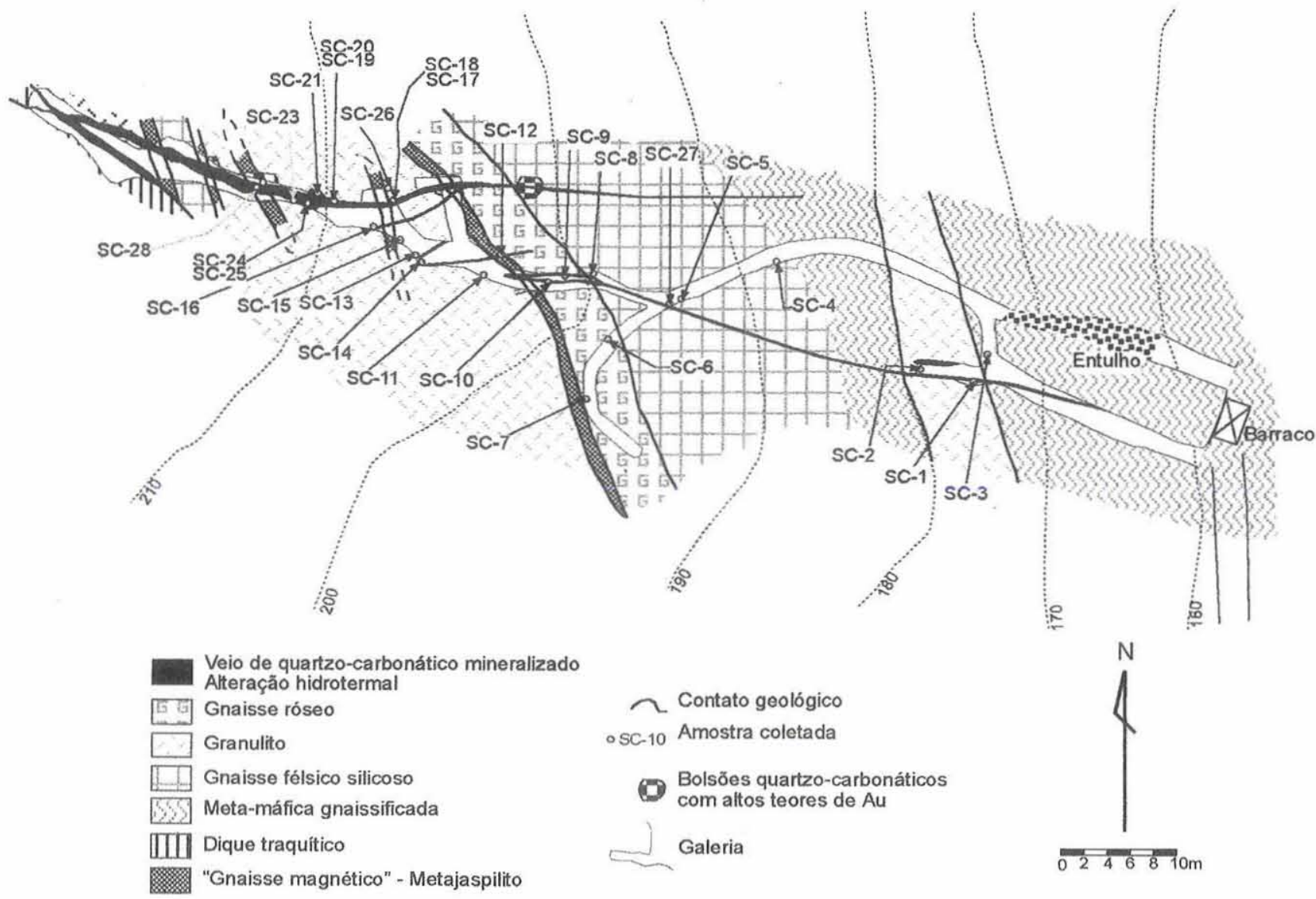

Fig. 3: Mapa geologico da mina de ouro Schramm. O ouro esta em veios de siderita-ankerita (altos teores) e de quartzo (teores muito baixos) encaixados por granulitos básicos e ultrabásicos e por gnaisses. Toda a região mineralizada está carbonatada, cloritizada e muscovitizada. 
junto secundário, com somente veios de quartzo ( $\mathrm{sem}$ veios de carbonato), formado por um enxame de veios e vênulas cujas espessuras individuais não ultrapassam $0,1 \mathrm{~m}$. Na maior parte das vezes os veios de quartzo têm aspecto manchado devido a presença de aglomerados centimétricos de siderita-ankerita (Fig. 4 B c C). É comum que os contatos entre a parte carbonatada $\mathrm{e}$ a parte quartzosa dos veios sejam ressaltados por uma franja de ripidolita-brunsvigita com cores negra e verde-escura (Fig. 4 D). Essas cloritas, como os carbonatos, também formam aglomerados dentro do quartzo.
O ouro concentrou-se em locais onde formaram-se bolsões alongados (Fig. 3 e 4 A), nos quais se misturam vênulas e veios de quartzo e carbonato. Esses bolsões apresentam-se verticalizados, com diâmetros médios entre 1,0 e 4,0 metros e comprimentos de uma a três dezenas de metros. Ocorrem em locais onde as encaixantes são granulitos ultrabásicos ou gnaisses magnetíticos. Nesses locais o ouro está praticamente todo nos veios de carbonato, cujos teores variam entre $500 \mathrm{e}$ cerca de $2.300 \mathrm{ppm}$. Nos veios de quartzo os teores raramente alcançam 1,0 ppm. A ausência de foliações ou deformações nos veios de
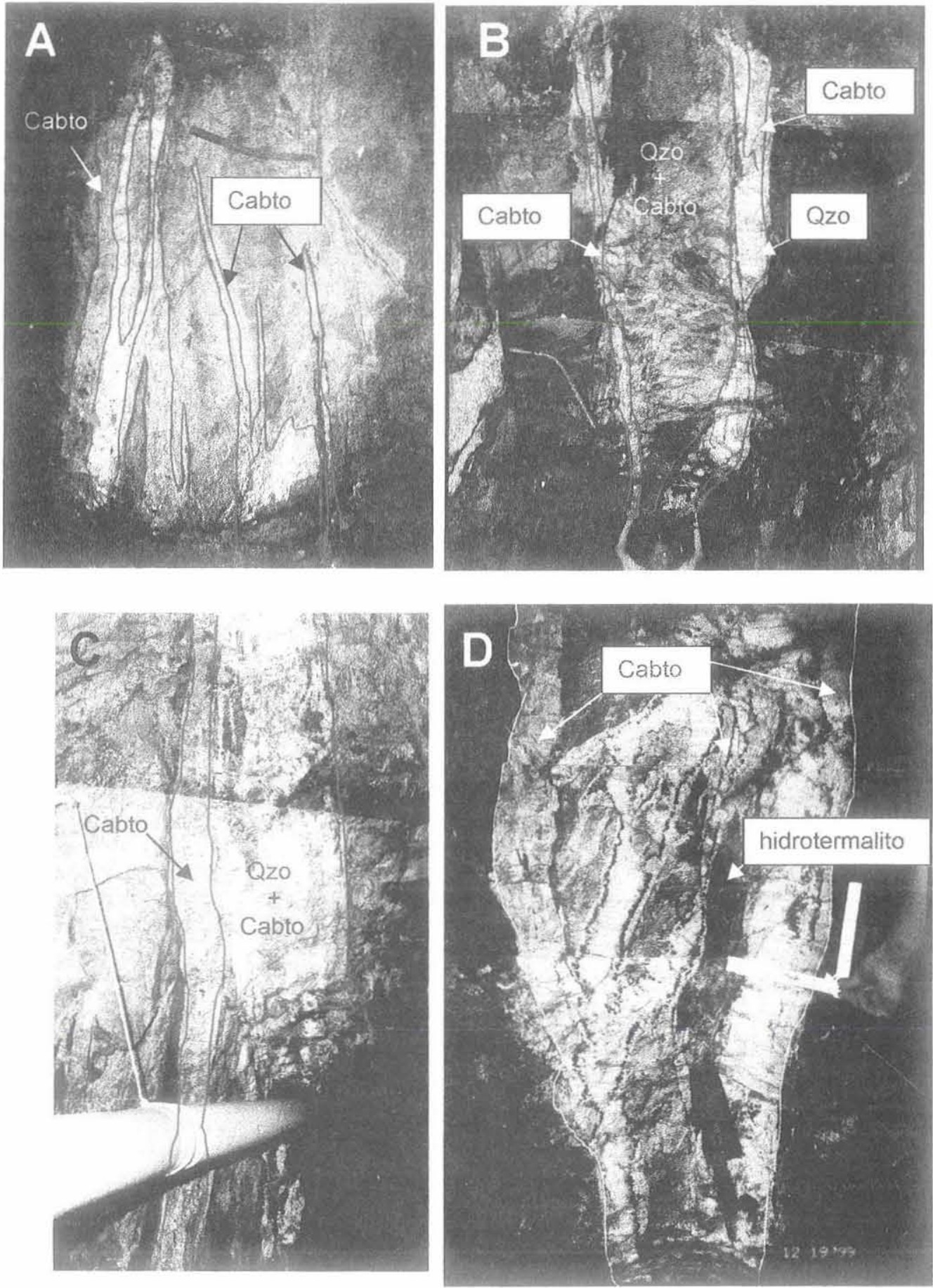

Fig. 4: Fotografias dos corpos mineralizados nas galerias da mina de ouro Schramm. São veios e vêmulas de siderita-ankerita e de quartzo leitoso com aglomerados de carbonatos e clorita. (A) Bolsão com alto teor de Au. comm cerca de $1.5 \mathrm{~m}$ de largura, no qual os veios de carbonato e de quartzo se misturam. (B) Veio central de quartzo e carbonato margeado, a esquerda, por veio macison de siderita-ankerita e. a direita, por outro veio de quartzo. (C) Veio macigo de siderita-ankerita em contato com veio de quartzo e carbonato. (D) Veios de carbonato ladeando veio de quarizo com lentes de carbonato e de gramulito carbonatizado. Os limites entre o quartzo (branco) e o carbonato (cinza) säo marcados por una franja negra ou verde escura de clorita (ripidolita-brunsvigita). Abreviacóes: Cabto = carbonatos ( siderita, ankerita e dolomita); $(y z)=$ quartzo. 
carbonato e de quartzo e nas suas encaixantes indicam que, após terem sido gerados, a região da mina Schramm não mais foi metamorfisada ou tectonizada.

Controle estrutural Biondi et al. (1992) apresentaram um estudo sobre as estruturas rígidas das áreas da Minepar, antiga proprietária do "veio do Schramm", cujas conclusões foram confirmadas pelas medidas feitas nas novas galerias da mina Schramm. Nesse estudo, falhas NS (Fig. 2) foram consideradas as principais transcorrências da área. Submetidas a uma compressão de SE para NW, inicialmente em regime transpressional levógiro, formou-se um sistema com sintéticas com moda $\mathrm{N} 3^{\circ} \mathrm{W}, 87^{\circ} \mathrm{NE}$, antitéticas a $\mathrm{N} 75^{\circ}-85^{\circ} \mathrm{E}, 87^{\circ} \mathrm{NW}$, falhas reversas a N $18^{\circ}-55^{\circ} \mathrm{E}, 6^{\circ}-15^{\circ} \mathrm{SE}$ e falhas extensionais a $\mathrm{N} 45^{\circ}-68^{\circ} \mathrm{W}, 72^{\circ} \mathrm{NE}$ a verticais. Nessa primeira fase de cisalhamento as fraturas extensionais, abertas (Schramm e Subida), foram mineralizadas. Ao final da compressão, o relaxamento do sistema causou a reversão localizada de algumas dessas falhas. Agora em regime transtensional dextrógiro, as mesmas falhas NS geraram um sistema onde as sintéticas têm atitudes $\mathrm{N} 30^{\circ}-35^{\circ} \mathrm{E}, 79^{\circ}-87^{\circ} \mathrm{NW}$, as antitéticas $\mathrm{N} 45^{\circ}-68^{\circ} \mathrm{W}, 72^{\circ} \mathrm{NE}$, as falhas compressionais são $\mathrm{N} 33^{\circ} \mathrm{W}, 43^{\circ} \mathrm{SW}$ e $\mathrm{N} 19^{\circ} \mathrm{E}, 31^{\circ} \mathrm{NW}$ c as extensionais $\mathrm{N} 75^{\circ}-85^{\circ} \mathrm{E}, 87^{\circ} \mathrm{NW}$, coincidentes com as atitudes dos veios de quartzo e dos diques riodacíticos do Grupo Itajaí. Ao final dessa fase, as falhas tensionais da primeira fase ocupam posiçōes de antitéticas, com pequenos deslocamentos reversos, tendo sido, por essc motivo, pouco acessíveis aos fluidos silicosos que geraram os veios de quartzo do Grupo Itajaí.

PETROLOGIA DAS ROCHAS E DO MINÉRIO Os veios mineralizados da mina Schramm estão em meio a rochas intensamente alteradas pelo fluidos que geraram os veios e a mineralização. As descriçōes de rochas inalteradas foram feitas sobretudo a partir de amostras coletadas fora da área da mina.

Petrologia das rochas encaixantes dos veios mineralizados Os granulitos do Complexo do Luiz Alves têm composições muito variadas, com 30-65\% de plagioclásios, $0-42 \%$ de ortoclásio, $0-50 \%$ de microclínio, $0-40 \%$ de quartzo, $0-10 \%$ de diopsídio, $0-60 \%$ de hornblenda, $0-10 \%$ de ortopiroxênio, $0-7 \%$ de biotita e até $4 \%$ de ilmeno-magnetita. Localmente foram identificados apatita, zircão, rutilo, clorita, epidoto, esfeno, actinolita, hematita, talco, serpentina e sericita. As porções básicas, noríticas, têm cores cinza esbranquiçadas, que variam até cores negras ou verde escuras nas partes com composições ultrabásicas, geralmente anfibolíticas (Fig. 2) ou enderbíticas. Em meio aos granulitos, geralmente em zonas falhadas e/ou cisalhadas, ocorrem lentes com dimensões variadas entre o metro e algumas centenas de metros, de migmatitos, de gnaisses rosados, de biotita gnaisses, de quartzitos e de formações ferríferas, além de blastomilonitos e protomilonitos derivados dessas rochas. Os veios da mina Schramm são quase todos encaixados por granulitos, mas tam- bém por gnaisses e por formações ferríferas bandadas ("gnaisses magnéticos”). Os gnaisses magnéticos são metajaspilitos granulares, bandados, com alternância de bandas escuras de magnetita e, algumas vezes, hematita (Fig. 9 A), e bandas de quartzo e albita (pouca). Em meio a magnetita há pirita e calcopirita anédricas (Fig. 9 B). Pirita euédrica, de cristalização tardia, provavelmente relacionada à mineralização, ocorre dispersa nessa e em outras rochas próximas aos veios da mina Schramm. O Tabela 1 resume a mineralogia atual dessas rochas, após modificadas pelas alterações hipogênicas, e os Tabelas 2, $3 \mathrm{e} 4$ mostram as sucessões das cristalizaçôes dos seus minerais.

A mineralogia da alteração hipogênica varia conforme a rocha original, mas a siderita e a ankerita estão sempre presentes e constituem a fase mineral que ocorre em maior volume. Esses carbonatos ocorrem em vênulas, junto ao quartzo (Fig. 5 C), ou como aglomerados ou cristais individuais dispersos na rocha (Fig. 5 B, D e E). Nos gnaisses, a matriz é sericitizada, silicificada e pouco cloritizada (Fig. 5 C), enquanto nos granulitos a cloritização predomina $\mathrm{em}$ relação a sericitização. Nos magnetita-gnaisses, embora cloritizados, sericitizados e carbonatizados, foi mantida a estrutura original do metajaspilito, com bandas paralelas alternadas de magnetita-hematita e de quartzo. A presença constante de cloritas, sericita, carbonatos e quartzo caracteriza uma paragênese de baixa temperatura, embora a presença de berilo nos biotita-gnaisses alterados sugira a possibilidade de terem ocorrido alguns fluxos fluidos de alta temperatura, talvez no início da fase de alteração (Tabelas 1 e 4). Os metajaspilitos (Tabelas $1 \mathrm{e} 2$ ) têm pirita, pirrotita e calcopirita intergranulares, anédricos, provavelmente originais da rocha. A alteração hipogênica cristalizou uma pirita euédrica tardia, também encontrada nos gnaisses alterados (Tabelas I e 4). A oxidação pervasiva dos gnaisses e granulitos (Tabelas 3 e 4), observada localmente, e a caulinização, também local, dos gnaisses, identificam uma fase de alteração hipogênica de menor temperatura que aquela que causou a carbonatação-sericitizaçãocloritização.

As Tabelas 5, $6 \mathrm{c} 7$ apresentam os teores das rochas inalteradas, das rochas com alterações hipogênicas e dos veios de carbonato e de quartzo da mina Schramm. A partir dos teores mostrados no Tabela 5 foi feita a figura 6 , na qual $\mathrm{A}, \mathrm{K}$ e F correspondem aos números de moles de $\mathrm{Al}_{2} \mathrm{O}_{3}$, de $\mathrm{K}_{2} \mathrm{O}+\mathrm{Na}_{2} \mathrm{O}+\mathrm{CaO}$ e de $\mathrm{FeO} *+\mathrm{MgO}+\mathrm{MnO}$, respectivamente. Como a alteração hipogênica dominante na mina Schramm é a carbonatação (siderita e ankerita), seguida da cloritização (ripidolita e brunsvigita), os pontos correspondentes as rochas com maior intensidade de alteração hipogênica devem ficar mais próximos do polo $\mathrm{F}$. A figura 6 mostra que há uma variação contínua da intensidade da alteração hipogênica desde os granitóides (gnaisses), mais distantes de F, atć os veios de carbonato maciços, com altos teores de Fe, $\mathrm{Mg}$ e $\mathrm{Mn}$ e por isso situados próximos ao vértice F. Os granulitos e os metajaspilitos, mais ricos $\mathrm{em} \mathrm{Fe} \mathrm{e} \mathrm{Mg} \mathrm{que} \mathrm{a} \mathrm{os} \mathrm{granitóides,} \mathrm{estão} \mathrm{situ-}$ ados nas laterais do domínio ocupado pelas rochas alteradas. Notar que os pontos correspondentes aos veios de quartzo formam um domínio

Tabela I: Paragêneses das rochas encaixamtes alteradas devido ao alojamento dos filōes de carbonatos e de quartzo que constituem os corpos mineralizados da mina Schramm (SC).

\begin{tabular}{|c|c|c|c|c|c|}
\hline \multicolumn{2}{|c|}{$\begin{array}{c}\text { Metajaspilito } \\
\text { (gnaisse a magnetita) }\end{array}$} & \multicolumn{2}{|c|}{$\begin{array}{c}\text { Metamáfica } \\
\text { (granulito básico) }\end{array}$} & \multicolumn{2}{|c|}{$\begin{array}{c}\text { Granitóide } \\
\text { (biotita gnaisse) }\end{array}$} \\
\hline $\begin{array}{c}\text { Minerais } \\
\text { Transparentes }\end{array}$ & $\begin{array}{l}\text { Minerais } \\
\text { metálicos }\end{array}$ & $\begin{array}{c}\text { Minerais } \\
\text { transparentes }\end{array}$ & $\begin{array}{l}\text { Minerais } \\
\text { metálicos }\end{array}$ & $\begin{array}{c}\text { Minerais } \\
\text { transparentes }\end{array}$ & $\begin{array}{l}\text { Minerais } \\
\text { metálicos }\end{array}$ \\
\hline Quartzo (***) & Magnetita (***) & Augita & Ilmenita & Quartzo (***) & Magnetita \\
\hline Siderita (***) & Hematita (*) & Hornblenda & $\begin{array}{l}\text { Óxido de } \\
\text { ferro (**) }\end{array}$ & Microclínio (*) & Hematita \\
\hline Ankerita (**) & Pirita euédrica (*) & Bitowinita & & Albita (**) & $\begin{array}{l}\text { Pirita cué- } \\
\text { drica (*) }\end{array}$ \\
\hline Ripidolita (**) & Pirita intergra-nular & Biotita & & Muscovita (***) & $\begin{array}{l}\text { Oxido de } \\
\text { ferro }(* *)\end{array}$ \\
\hline Brunsvigita (*) & Calcopirita & Ripidolita ("惊水) & & Clinocloro (*) & \\
\hline Penina $(* *)$ & & Brunsvigita (**) & & Penina (*) & \\
\hline Stilpnomelano & & Siderita (***) & & Siderita (**) & \\
\hline Biotita & & Ankerita (**) & & Ankerita (*) & \\
\hline Esfeno & & Albita (**) & & Berilo & \\
\hline Muscovita ("k*k) & & & & Pirofilita & \\
\hline
\end{tabular}

(***) Muita (**) Comum (*) Pouco ( ) Raro


Tabela 2: Sucessão de cristalizaşão dos minerais de alterạ̦ão hipogênica dos metajaspilitos encaixantes dos veios mineralizados na mina Schramm.

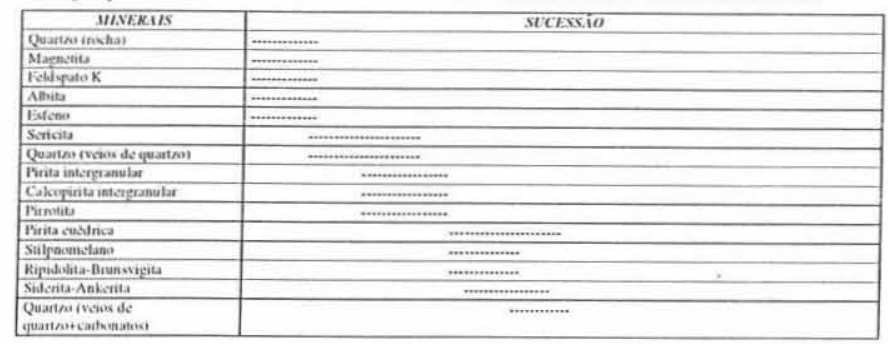

Tabela 3: Sucessão de cristalização dos minerais de alteraşão hipogênica das metamáficas (granulitos básicos) encaixantes dos veios mineralizados na mina Schramm.

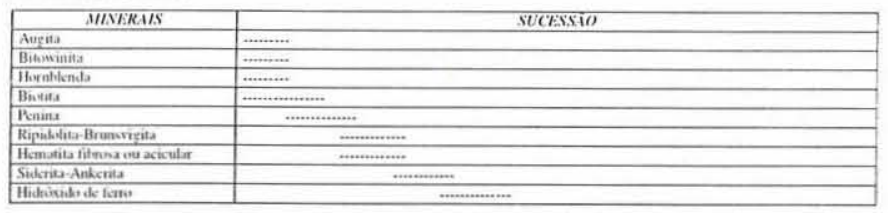

que envolve o dos veios carbonáticos e é envolvido pelo das rochas alteradas, o que indica que sempre há siderita e ankerita misturadas ao quartzo dos veios.

Os teores em elementos traços (Tabelas 6), após normalizados com os chondritos de Thompson (1982), foram usados para construir a figura 7. Comparando rochas inalteradas com as alteradas, nota-se que: (a) As formas gerais dos diagramas de distribuição dos elementos litófilos e incompatíveis das rochas alteradas e inalteradas são sempre

Tabela 4: Sucessão de cristalização dos minerais de alteraşão hipogênica dos granitóides encaixantes dos veios mineralizados na mina Schramm.

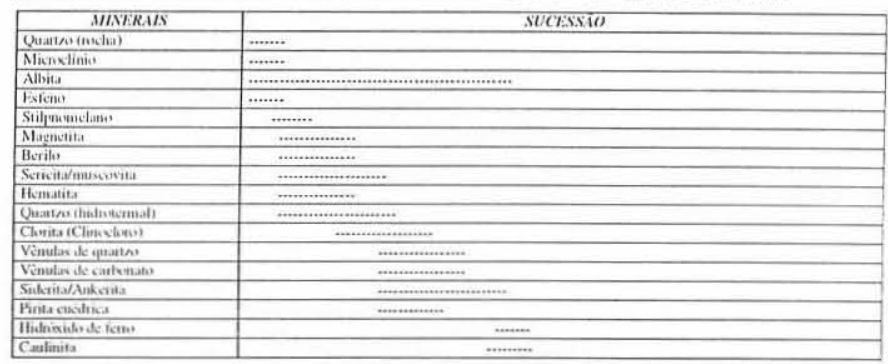

Tabela 5: Mina Schramm - Teores das rochas e dos veios de minério em elementos maiores. Atenșĩo: (a) Teores em Fe ou em Fe $\mathrm{O}_{3} \mathrm{O}_{3}$ que estão entre parênteses não integram o total da análise. Em todas as amostra o ferro foi analisado como "ferro total". na forma de $\mathrm{Fe}_{2} \mathrm{O}_{3}$ (ferro oxidado, em silicatos, carbonatos e óxidos) ou de Fe (ferro reduzido, em sulfetos). (b) Análises feitas por FRX = fluorescência de raios X - não têm valores de "perda ao fogo" - P.F: = n.d. O "fechamento" dessas análises (total dos teores) pode ser incompleto ou $>100 \%$.

\begin{tabular}{|c|c|c|c|c|c|c|c|c|c|c|c|c|c|}
\hline \multirow[t]{2}{*}{ Amostra } & $\mathrm{SiO}_{2}$ & $\mathrm{Al}_{2} \mathrm{O}_{3}$ & $\mathrm{TiO}_{2}$ & $\mathrm{Fe}_{2} \mathrm{O}_{3}$ & $\mathrm{MnO}$ & $\mathrm{MgO}$ & $\mathrm{CaO}$ & $\mathrm{Na}_{2} \mathrm{O}$ & $\mathrm{K}_{2} \mathrm{O}$ & $\mathrm{P}_{2} \mathrm{O}_{5}$ & P.F. & $\mathrm{s}$ & Total \\
\hline & $(\%)$ & $(\%)$ & $(\%)$ & $(\%)$ & $(\%)$ & $(\%)$ & $(\%)$ & (\%) & $(\%)$ & (\%) & $(\%)$ & $(\%)$ & (\%) \\
\hline \multicolumn{14}{|c|}{ Rochas, näo alteradas, encaixamtes dos veios de quartzo e carbonato } \\
\hline $\mathrm{SC}-41$ & 74,5 & 14,3 & 0,13 & 2,0 & 0,05 & 0,45 & 2,6 & 3,9 & 1,6 & $0,0+4$ & 0.73 & 0,02 & 100,32 \\
\hline SC-34 & 50,8 & 12,2 & 0,89 & 13,1 & 0,26 & 8.3 & 10.6 & 2,5 & 0,75 & 0,09 & 0,12 & 0,05 & 99,65 \\
\hline SC- -32 & 65,8 & 3,4 & 0.53 & 20.1 & 0.49 & 6,4 & 1.0 & 0.64 & 0.11 & 0,08 & $\begin{array}{c}<0,0 \\
1\end{array}$ & 0,27 & 98,82 \\
\hline SC- -39 & 75.7 & 13,4 & 0,04 & 2.1 & 0,03 & $<0,10$ & 0,36 & 3,2 & 4.6 & 0,02 & 1,03 & 0,01 & 100,49 \\
\hline SC-33 & 74,0 & 13,4 & 0.08 & 1.3 & 0.02 & $<0.10$ & 0.29 & 2.5 & 6.4 & $<0,01$ & 0.40 & $<0,01$ & 98,39 \\
\hline SC-10 & 70,6 & 15,20 & 0.20 & 2,9 & 0,29 & 0.45 & 2.12 & 2.28 & 4,47 & 0.06 & n.d. & $<0.01$ & 98.61 \\
\hline SC-07 & 73,7 & 13.83 & 0,19 & 2.0 & 0.06 & 0.36 & 1.41 & 3.8 & 3,6 & 0.04 & 0,76 & 0.02 & 99.77 \\
\hline \multicolumn{14}{|c|}{ Rochas com alterações hipogênicas } \\
\hline $\mathrm{SC}-3 \mathrm{IB}$ & 38,43 & 12.34 & 1,97 & 34.23 & 1.33 & 5.57 & 0.91 & 0.04 & 0.28 & 0.33 & n.d. & 1,30 & 86.44 \\
\hline SC-28E & 50,6 & 0.78 & 0,09 & 41,7 & 1.2 & 0.93 & 0.79 & & 0.01 & 0.10 & 2,73 & 0,60 & 99,53 \\
\hline SC-24B & 48,56 & 20,14 & 0,65 & 12,80 & 2,07 & 2.28 & 1.79 & 0.13 & 5,87 & 0,46 & n.d. & 0,43 & 95,18 \\
\hline SC-24A & 6.8 & 0,48 & 0,01 & 44,42 & 13.6 & 4,97 & 10,98 & 0.02 & 0,10 & 0,00 & 31,9 & 0,09 & 99.93 \\
\hline SC-22 & 57,2 & 17,2 & 0,55 & 5,00 & 0.45 & 2,4 & 5,92 & 2,7 & 2,5 & 0,22 & 6,01 & 0,09 & 98,74 \\
\hline SC-2I & 43,6 & 17,6 & 1.69 & 7,43 & 0.31 & 3,5 & 5.26 & 2,1 & 4,1 & 1,06 & n.d. & 0.11 & 92,90 \\
\hline SC-20 & 45,96 & 17,92 & 1,33 & 13,55 & 1,98 & 2,66 & 3,65 & 0,12 & 5,12 & 0,84 & n.d. & 1.18 & 94,31 \\
\hline SC-19 & 46,76 & 12,11 & 0.98 & 19.63 & 4.86 & 3,62 & 1.38 & 0.08 & 3,58 & 0,63 & n.d. & 0,42 & 94,06 \\
\hline SC-18 & 49,86 & 15,17 & 1,18 & 17,01 & 0.96 & 4.76 & 4.86 & 4.39 & 0,45 & 0.74 & n.d. & $<0,01$ & 99.39 \\
\hline SC-17 & 44,08 & 18,43 & 1,50 & 14,90 & 2,82 & 2,79 & 3.48 & 0,11 & 5,25 & 1.44 & n.d. & 0,93 & 95,73 \\
\hline SC-16 & 49,4 & 14,4 & 0,86 & 6,29 & 0,17 & 7.6 & 9,29 & 2.7 & 0.76 & 0,13 & n.d. & 0,06 & 95.45 \\
\hline SC-15 & 49,13 & 2,97 & 1,43 & 44,64 & 0.17 & 2,81 & 2,37 & 0,05 & 0,02 & 0,16 & n.d. & 1,13 & 104,88 \\
\hline SC-14 & 43,84 & 10.05 & 0,72 & 24.03 & 0.38 & 12,19 & 4,59 & 0.08 & 0.77 & 0,15 & in.d. & $<0.01$ & 96,80 \\
\hline SC-13B & 39,54 & 6,79 & 1.30 & 32.60 & 2.71 & 3,86 & 4,92 & 0.04 & 0.59 & 0,25 & n.d. & 3,09 & 95,69 \\
\hline$S C-13 A$ & 46,08 & 20.64 & 1.29 & 13,50 & 0,79 & 5.27 & 5.19 & 1.75 & 3,46 & 0.33 & n.d. & 0.30 & 98,60 \\
\hline SC-12 & 49.01 & 7.10 & 0,67 & 29,87 & 0.20 & 4,31 & 3.42 & 0.78 & 0.34 & 0.20 & n.d. & 1.87 & 97.77 \\
\hline SC-11 & 45,3 & 2,0 & 1.1 & 48.7 & 0.08 & 2.0 & 0.24 & 0.05 & 0.09 & 0,13 & n.d. & 0.03 & 99.72 \\
\hline SC-09 & 67,89 & 11.59 & 0.22 & 4,80 & 0.72 & 0.58 & 0,26 & 0.09 & 3,95 & 0,04 & n.d. & 0.33 & 90,47 \\
\hline SC-02 & 63,06 & 3.85 & 2.58 & 25,72 & 0.18 & 1.22 & 0.05 & 0.04 & 0,00 & 0.01 & n.d. & 0.51 & 97.22 \\
\hline SC-01A & 58,25 & 1.09 & 0.84 & 40,82 & 0.42 & 0.55 & 0.17 & 0.04 & 0,03 & 0.06 & n.d. & $<0.01$ & 102,27 \\
\hline \multicolumn{14}{|c|}{ Veio de quartzo } \\
\hline SC-28M & 93.85 & 0.13 & 0.01 & 1.97 & 0.11 & 0.20 & 0.16 & 0.06 & $<0.01$ & $<0,01$ & n.d. & $<0.01$ & 96.49 \\
\hline SC-28L & 78.69 & 0,30 & 0.01 & 10.01 & 3.13 & 1,57 & 1.20 & 0.04 & $<0.01$ & $<0,01$ & n.d. & $<0,01$ & 94.96 \\
\hline SC-28K & 93,1 & 0,20 & 0.01 & 6.4 & 0.12 & 0.19 & 0.13 & 0.06 & 0.01 & $<0.01$ & n.d. & $<0.01$ & 100,25 \\
\hline SC-28J & 76.55 & 0.38 & 0.01 & 14.85 & 4.43 & 2.31 & 2.07 & 0.04 & 0.01 & $<0.01$ & n.d. & 0.19 & 100.65 \\
\hline SC-25B & 81.12 & 0.90 & 0.01 & 13,32 & 1.44 & 0.52 & 2.76 & 0.04 & $<0.01$ & $<0.01$ & n.d. & 0.15 & 100.26 \\
\hline SC-25A & 92,2 & 0,30 & 0.01 & 5.14 & 0.32 & 0,20 & 0.43 & 0.06 & 0.05 & $<0.01$ & 2.29 & $<0.01$ & 99.47 \\
\hline $\mathrm{SC}-23 \mathrm{~A}$ & 92,87 & 0.34 & 0.01 & 2,76 & 0.12 & 0,39 & 0,48 & 0,05 & $<0,01$ & $<0,01$ & n.d. & $<0,01$ & 97,02 \\
\hline \multicolumn{14}{|c|}{ Veio de carbonato (siderita + ankerita + dolomita) } \\
\hline \multirow[t]{2}{*}{ Amostra } & $\mathrm{SiO}_{2}$ & $\mathrm{Al}_{2} \mathrm{O}_{3}$ & $\mathrm{TiO}_{2}$ & $\mathrm{Fe}_{2} \mathrm{O}_{3}$ & $\mathrm{MnO}$ & $\mathrm{MgO}$ & $\mathrm{CaO}$ & $\mathrm{Na}_{2} \mathrm{O}$ & $\mathrm{K}_{2} \mathrm{O}$ & $\mathrm{P}_{2} \mathrm{O}_{5}$ & P.F. & $\mathrm{S}$ & Total \\
\hline & $(\%)$ & $(\%)$ & $(\%)$ & $(\%)$ & $(\%)$ & $(\%)$ & $(\%)$ & $(\%)$ & $(\%)$ & $(\%)$ & $(\%)$ & $(\%)$ & $(\%)$ \\
\hline SC-280 & 1.7 & 0,16 & 0.01 & 66,41 & 12.50 & 6,2 & 0,49 & 0,04 & $<0.01$ & $<0,01$ & 33.7 & 0,16 & 101,37 \\
\hline SC-28N & 1,2 & 0,19 & 0,01 & 66,94 & 13.10 & 5,6 & 0,56 & 0.02 & 0,01 & $<0,01$ & 33,7 & 0,18 & 101.42 \\
\hline SC-28G & 1,8 & 0,19 & 0,01 & 60,71 & 12,59 & 7,3 & 0,85 & 0,04 & $<0,01$ & $<0,01$ & n.d. & 1.19 & 84,71 \\
\hline SC-23B & 12.05 & 0.90 & 0,02 & 47,41 & 10,72 & 6.73 & 6.78 & 0,05 & 0,01 & $<0,01$ & n.d. & $<0,01$ & 84,67 \\
\hline
\end{tabular}


muito parecidas, com exceção dos teores de potássio. A alteração hipogênica, portanto, não acarretou mudanças significativas nos teores. (b) A figura 7A mostra que, nos granulitos, a alteração hipogênica aumentou os teores de todos os elementos litófilos e incompatíveis. (c) Nos gnaisses a alteração causou a lixiviação do $\mathrm{K} \mathrm{e}$ aumentou os teores de $\mathrm{Zr}$, Ti, Y e Yb (Fig. 7 B). (d) O K, junto do $\mathrm{Ce}, \mathrm{Nd} \mathrm{e}$ do $\mathrm{Yb}$, foi, também, lixiviado dos metajaspilitos (Fig. 7D), enquanto os teores de $\mathrm{Zr}$ aumentaram.

Petrologia dos veios de carbonato e de quartzo (minérios) ELEMENTOS TRAÇOS DE TENDÊNCIAS LITÓFILAS E IN-
COMPATIVEIS Os teores em elementos litófilos e incompatíveis (Tabela 6) da siderita-ankerita dos veios (Fig. $7 \mathrm{C}$ ) praticamente não mudam quando o veio é estéril ou é mineralizado. Esses carbonatos têm anomalias positivas, fortes, em Rb, Ce e Nd e negativa de Ba e de $\mathrm{P}$. Comparando as figuras $7 \mathrm{C} \mathrm{e} 7 \mathrm{E}$ nota-se que o padrão de distribuição dos elementos traços nos carbonatos dos veios é muito diferente daquele do quartzo, o que sugere que esses veios se formaram a partir de fluidos diferentes.

ELEMENTOS TRAÇOS DE TENDÊNCIAS CALCÓFILAS E METAIS RAROS O Tabela 7 mostra os teores em elementos de tendências
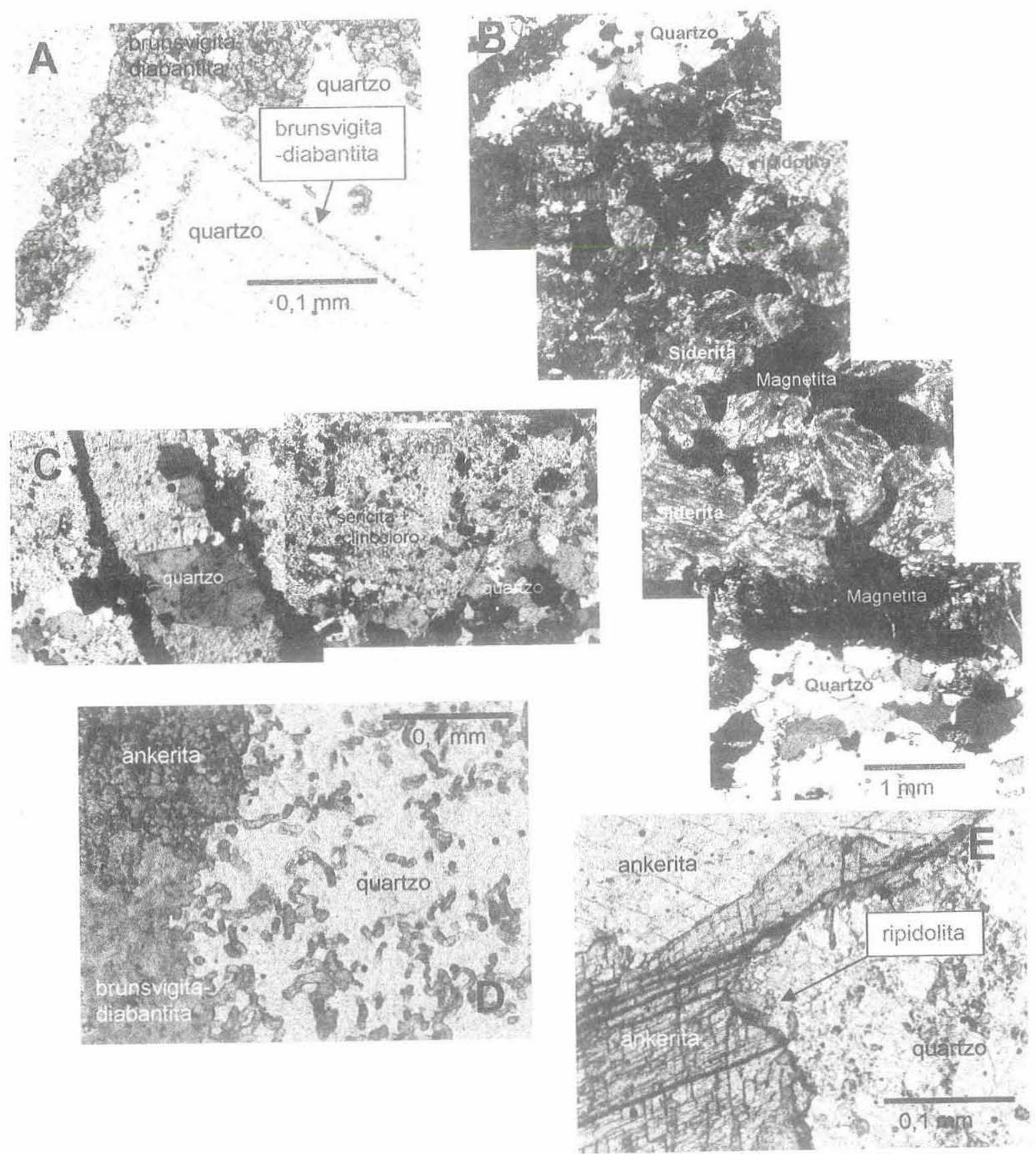

Fig. 5. Imagens de lâminas delgadas de rochas da mina de ouro Schramm. (A) Aglomerados de brunsvigita-diabantita em meio aos cristais de quartzo do veio

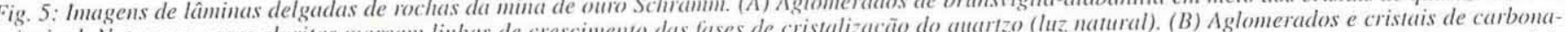

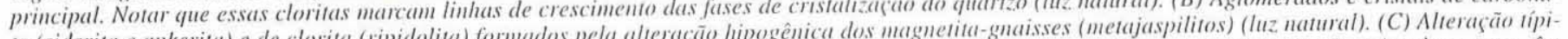

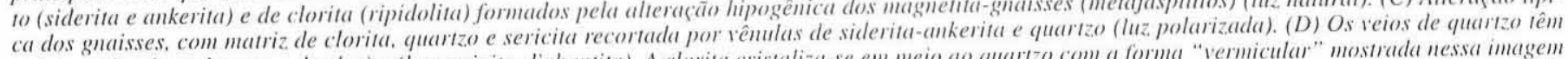

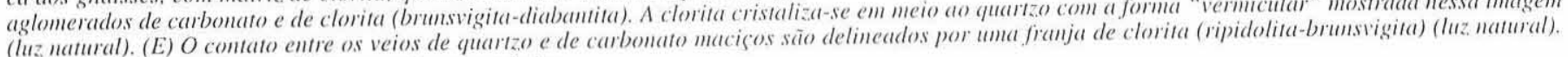
lsto foi destacado na figura $4 \mathrm{D}$ em escala mesoscópica. 


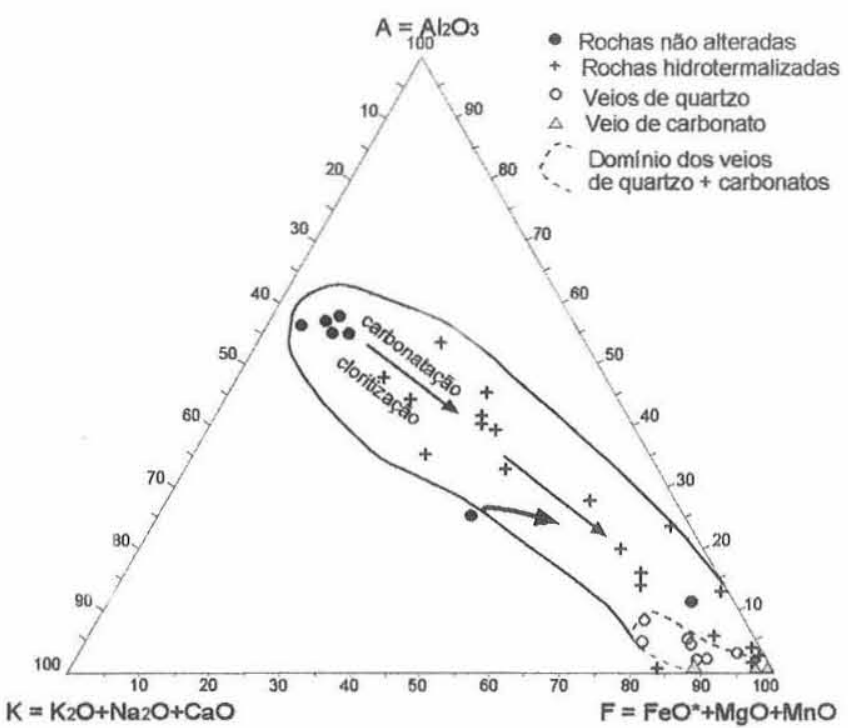

Fig. 6: Triângulo $\mathrm{Al}_{2} \mathrm{O}_{3}(\mathrm{~A}) \times \mathrm{K}_{2} \mathrm{O}+\mathrm{Na}_{2} \mathrm{O}+\mathrm{CaO}(\mathrm{K}) \times \mathrm{FeO}+\mathrm{MgO}^{2} \mathrm{MnO}(\mathrm{F})$ das rochas e minérios da mina Schramm (em moles\%). Esta figura mostra que a carbonatação e a cloritizașão são as alterações hipogênicas dominamtes Há um aumeto contínuo de $\mathrm{FeO}+\mathrm{MgO}+\mathrm{MnO}$ das rochas em direşão ao polo F. desde as rochas inalteradas (granitóides ou granulitos) até os veios maciços de carbonato. Notar que os veios de quartzo também têm carbonatos. calcólilas e em metais raros dos veios carbonáticos, dos veios de quartzo e das rochas com alterações hipogênicas. Notar (Tabela 7 e Fig. 8 A) que, junto ao ouro, também concentram-se, em altos teores, a prata (150 a $300 \mathrm{ppm})$, o arsênio $(0,15$ a $0,60 \%)$ e o níquel $(0,01$ a $1,4 \%)$. Em menores proporções o minério tem Zn (250 a 1600 ppm), Pb (100 a $850 \mathrm{ppm}$ ) e Co (40 a $750 \mathrm{ppm})$. Os teores de Sb, Te, Se, W, Mo e Bi são muito baixos, próximos ou menores que $10 \mathrm{ppm}$. Os veios de quartzo dos bolsões têm teores de ouro de até 1 ppm (Tabela 7 e Fig. $8 \mathrm{~B}$ ) e de As, $\mathrm{Zn}, \mathrm{Pb}, \mathrm{Ni}, \mathrm{Cu}, \mathrm{Co}, \mathrm{Mo}, \mathrm{Te}$, e Bi entre 1 e 50 ppm. Fora das regiões mineralizadas os teores de Au são menores que $50 \mathrm{ppb}$ e os teores dos outros elementos são maiores que os da zona mineralizada (Tabela 7 e Fig. 8 B), variando entre 10 e 900 ppm. Raramente as rochas com alterações hipogênicas têm ouro e a presença do ouro em teores acima de $50 \mathrm{ppb}$ não traz um aumento significativo nos teores dos outros elementos (Tabela 7 e Fig. $8 \mathrm{C}$ ), cujos teores variam entre 1 e 200 ppm.

MINERALOGIA DOS VEIOS DE CARBONATO E DE QUARTZO Os veios de quartzo sempre têm aglomerados de siderita-ankerita e de clorita (brunsvigita-diabantita, Fig. 5 A e D). Os fluxos sucessivos de lluidos silicosos que geraram os veios de quartzo sempre cristalizaram a clorita junto ao quartzo, causando o aparecimento de linhas de crescimento dos cristais de quartzo ressaltadas por franjas de brusnvigitadiabantita (Fig. 5 A). Em meio ao quartzo, a clorita forma cristais tubulares ou "vermiculares" (fig. 5 D) que coalescem formando aglo-

Tabela 6: Mina Schramm - Teores das rochas e dos veios de minério em elementos trạ̧os de tendência litófila.. Todas as amostras foram analisadas também para Sn, W e Be e os teores foram menores que os limites de deteç̧ão $(<10 \mathrm{ppm},<10 \mathrm{ppm}$ e $<1$ ppm, respectivamente)

\begin{tabular}{|c|c|c|c|c|c|c|c|c|c|c|c|c|}
\hline Amostra & $\mathrm{Cr}$ & $\mathrm{Zr}$ & $\mathrm{V}$ & $\mathrm{Sc}$ & $\mathrm{Se}$ & $\mathrm{F}$ & $\mathrm{Rb}$ & $\mathrm{Li}$ & $\mathrm{Cd}$ & $\mathrm{Ba}$ & $\mathrm{Y}$ & $\mathrm{La}$ \\
\hline & $(\mathrm{ppm})$ & $(\mathrm{ppm})$ & $(\mathrm{ppm})$ & $(\mathrm{ppm})$ & $(\mathrm{ppm})$ & $(\mathrm{ppm})$ & $(\mathrm{ppm})$ & $(\mathrm{ppm})$ & $(\mathrm{ppm})$ & $(\mathrm{ppm})$ & $(\mathrm{ppm})$ & $(\mathrm{ppm})$ \\
\hline \multicolumn{13}{|c|}{ Rochas encaixantes dos veios de quartzo e carbonato } \\
\hline SC-4I & 52 & 1 & 11 & $<1$ & $<1$ & 190 & $<1$ & 4 & $<1$ & 79 & 1 & 15 \\
\hline SC-39 & 56 & 2 & 4 & $<1$ & $<1$ & 100 & $<1$ & $<1$ & $<1$ & 91 & 3 & 23 \\
\hline SC-34 & 248 & 6 & 118 & 10) & $<1$ & 1550 & $<1$ & 1.9 & 4 & 107 & 24 & 30 \\
\hline SC-33 & 45 & 2 & $<3$ & $<1$ & $<1$ & 120 & $<1$ & 4.8 & $<1$ & 139 & 3 & 28 \\
\hline SC-32 & 85 & \begin{tabular}{|c|}
3 \\
\end{tabular} & 62 & 2.9 & $<1$ & 120 & $<1$ & $<1$ & 7 & 58 & 12 & II \\
\hline \multicolumn{13}{|c|}{ Rochas com alteraçôes hipogênicas } \\
\hline SC-31B & $<1$ & 36 & $<3$ & $<1$ & $<1$ & $<10$ & 9 & $<1$ & 47 & $<1$ & 12 & $<10$ \\
\hline SC-29C & $<1$ & 11 & $<3$ & $<1$ & $<1$ & 712 & $<1$ & $<1$ & 47 & $<1$ & 38 & $<10$ \\
\hline SC-29A & $<1$ & 13 & $<3$ & $<1$ & $<1$ & $<10$ & $<1$ & $<1$ & 39 & $<1$ & 11 & $<10$ \\
\hline SC-28P & $<1$ & 10 & $<3$ & $<1$ & $<1$ & 4 & $<1$ & $<1$ & 56 & $<1$ & 10 & $<10$ \\
\hline SC-28E & 56 & 9 & 24 & $<1$ & $<1$ & 210 & $<1$ & 1.6 & 33 & 7 & 8 & 12 \\
\hline SC-24A & $<1$ & 8 & 14 & $<1$ & $<1$ & 84 & $<1$ & $<1$ & 35 & 6 & 12 & 14 \\
\hline SC-22 & 31 & 99 & 38 & 3 & $<1$ & 740 & 95 & 17 & 4 & 88 & 9 & 38 \\
\hline SC-21 & 17 & 366 & 57 & 4 & $<1$ & 1400 & 127 & 17 & 7 & 95 & 21 & 69 \\
\hline SC-20 & $<1$ & 232 & $<3$ & $<1$ & $<1$ & 391 & 127 & $<1$ & 35 & $<1$ & 29 & $<10$ \\
\hline SC-19 & $<1$ & 138 & $<3$ & $<1$ & $<1$ & 830 & 87 & $<1$ & 41 & $<1$ & 21 & $<10$ \\
\hline SC-18 & $<1$ & 146 & $<3$ & $<1$ & $<1$ & 342 & 15 & $<1$ & 33 & $<1$ & 19 & $<10$ \\
\hline SC-17 & $<1$ & 190 & $<3$ & $<1$ & $<1$ & 698 & 148 & $<1$ & 37 & $<1$ & 30 & $<10$ \\
\hline SC-16 & 148 & 71 & 84 & 11 & 1 & 1500 & 24 & 15 & 5 & 41 & 8 & 34 \\
\hline SC-15 & $<1$ & 18 & $<3$ & $<1$ & $<1$ & $<10$ & 1 & $<1$ & 60 & $<1$ & 14 & $<10$ \\
\hline SC-14 & $<1$ & 45 & $<3$ & $<1$ & $<1$ & 1030 & 47 & $<1$ & 38 & $<1$ & 33 & $<10$ \\
\hline$S C-13 B$ & $<1$ & 60 & $<3$ & $<1$ & $<1$ & $<10$ & 17 & $<1$ & 50 & $<1$ & 15 & $<10$ \\
\hline$S C-13 A$ & $<1$ & 205 & $<3$ & $<1$ & $<1$ & 523 & 99 & $<1$ & 33 & $<1$ & 25 & $<10$ \\
\hline SC- 12 & $<1$ & 308 & $<3$ & $<1$ & $<1$ & 325 & 6 & $<1$ & 46 & $<1$ & 14 & $<10$ \\
\hline SC-11 & 94 & 11 & 127 & 4,3 & $<1$ & 350 & $<1$ & 4.1 & 37 & 9 & 11 & $<10$ \\
\hline SC-10 & $<1$ & 213 & $<3$ & $<1$ & 1 & 516 & 90 & $<1$ & 24 & $<1$ & 20 & $<10$ \\
\hline SC-09 & $<1$ & 185 & $<3$ & $<1$ & 1 & 1015 & 118 & $<1$ & 25 & $<1$ & 21 & $<10$ \\
\hline SC-07 & 27 & 229 & 9.4 & $<1$ & 1 & 200 & 42 & 3.5 & $<1$ & 71 & 3 & 30 \\
\hline SC-02 & $<1$ & 41 & $<3$ & $<1$ & $<1$ & $<10$ & $<1$ & $<1$ & 46 & $<1$ & 10 & $<10$ \\
\hline SC-01A & $<1$ & 15 & $<3$ & $<1$ & $<1$ & 210 & $<1$ & $<1$ & 5.5 & $<1$ & 9 & $<10$ \\
\hline \multicolumn{13}{|c|}{ Veios de quartzo } \\
\hline SC-28M & $<1$ & 6 & $<3$ & $<1$ & 1 & 1492 & $<1$ & $<1$ & 19 & $<1$ & 6 & $<10$ \\
\hline SC-28L & $<1$ & 6 & $<3$ & $<1$ & 1 & 103 & $<1$ & $<1$ & 30 & $<1$ & 10 & $<10$ \\
\hline SC-28K & 234 & 2 & 3 & $<1$ & 1 & 74 & $<1$ & $<1$ & 4 & 2 & $<1$ & $<10$ \\
\hline SC-28J & $<1$ & 8 & $<3$ & $<1$ & $<1$ & $<10$ & $<1$ & $<1$ & 36 & $<1$ & 13 & $<10$ \\
\hline SC-25B & $<1$ & 8 & $<3$ & $<1$ & $<1$ & $<10$ & $<1$ & $<1$ & 36 & $<1$ & 11 & $<10$ \\
\hline SC- $25 \mathrm{~A}$ & 59 & 2 & 3 & $<1$ & 1 & 40 & 4 & $<1$ & 3 & 4 & 2 & $<10$ \\
\hline SC-23A & $<1$ & 7 & & $<1$ & 1 & 1521 & $<1$ & $<1$ & 20 & $<1$ & 7 & $<10$ \\
\hline \multicolumn{13}{|c|}{ Veios de carbonato (siderita + ankerita + dolomita) } \\
\hline SC-280 & 5 & 9 & 10 & 1.4 & 3 & $<10$ & 28 & $<1$ & 37 & 2 & 7 & 11 \\
\hline SC-28N & $<1$ & 8 & 10 & $<1$ & $<1$ & 52 & 3 & $<1$ & 31 & 3 & 7 & 10 \\
\hline SC-28G & 5 & 8 & 26 & $<1$ & 18 & 50 & 64 & $<1$ & 32 & 2 & 11 & 12 \\
\hline SC-24B & $<1$ & 113 & $<3$ & $<1$ & $<1$ & $<10$ & 140) & $<1$ & 35 & $<1$ & 30 & $<10$ \\
\hline SC-23B & $<1$ & 10 & $<3$ & $<1$ & $<1$ & $<10$ & 0 & $<1$ & 59 & $<1$ & 21 & $<10$ \\
\hline
\end{tabular}



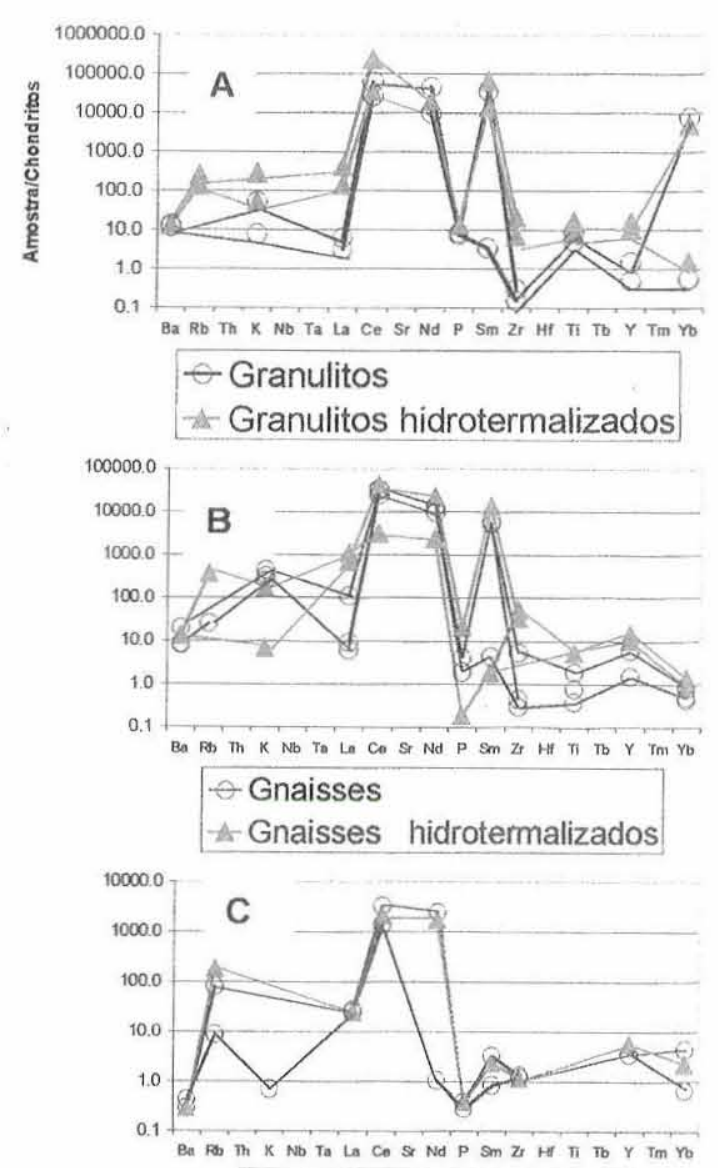

- Veio carbonático
—-Veio carbonático com Au
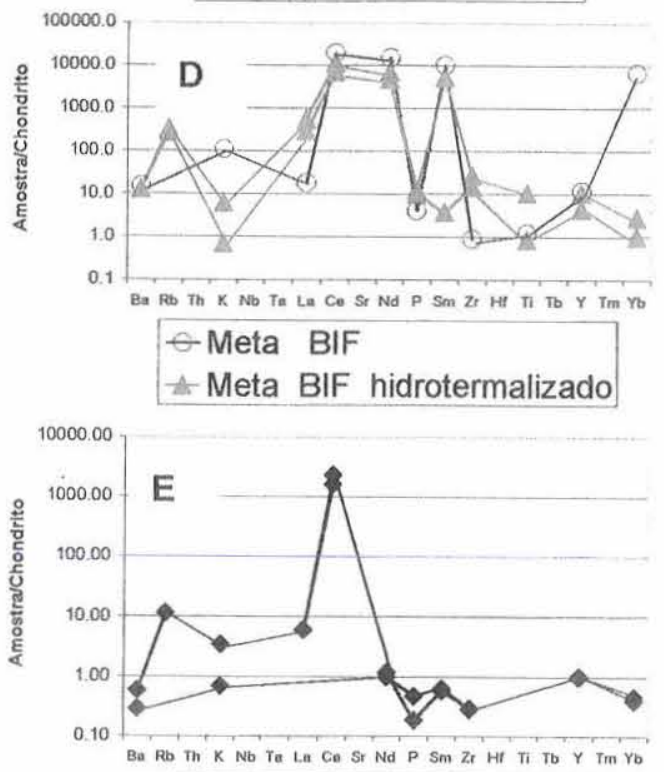

Veio de quartzo principal
Fig. 7: Distribuição dos teores em elementos com tendências litófilas e incompatíreis de rochas e minérios da mina Schramm, normalizados peio chondrito de Thompson (1982). A comparação entre os teores das rochas inalteradas e alteradas mostra que, com a exceşão do potássio, a alterașão hipogênica não causou mudancas significativamente nos teores dos gramulitos (A), dos gnaisses (B) e dos metajaspilitos (D). O mesmo pode ser dito quando se comparam os teores dos veios carbonatados come e sem Au (C). Em (E) é mostrada a distribuição dos elementos no quartzo dos veios, muito diferentes daquela dos carbonatos $(C)$. merados (Fig. 5 D). Quando veios de quartzo e de carbonato estâo juntos (Fig. 4), os contatos são ressaltados por uma franja de clorita (Fig. 4 D e 5 E).

Praticamente o único sulfeto encontrado disperso $\mathrm{em}$ todos os veios de quartzo e de carbonato é a pirita cuédrica, cristalizada tardiamente (Tabcla 4). Nos bolsões com altos teores de ouro, a quantidade total de sulfetos é menor que $0,5 \% \mathrm{~cm}$ volume, e restringe-se aos veios de siderita-ankerita. A paragênese sulfetada é complexa e, conforme indicado pela química do minério, composta essencialmente por sulfetos de $\mathrm{Ni}$ e As secundados pelos de $\mathrm{Co}, \mathrm{Zn}$ e Cu. A descrição de seçōes polidas $\mathrm{e}$ as análises com microssonda eletrônica (Laboratório de Microssonda da UFRGS) mostraram as presenças de ouro livre, galena, calcopirita, arsenopirita (muito rara), esfalerita, pirita níquelcobaltílera, pirita, siegenita-violarita, millerita, gersdorfita, um

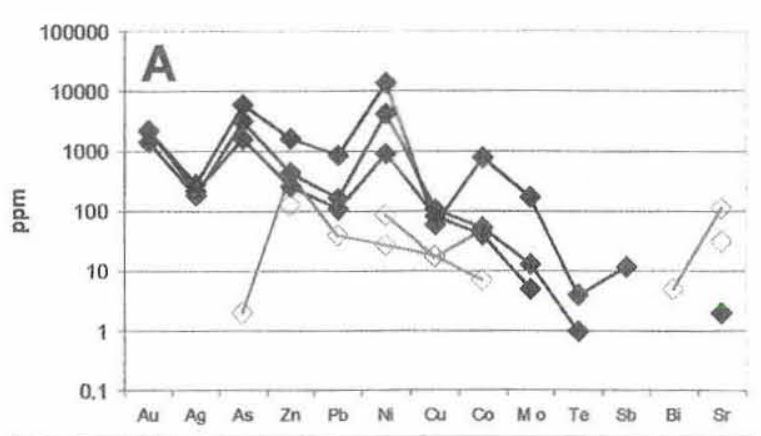

- Veio carbonático-Alto teor $\mathrm{Au} \rightarrow$ Veio carbonático-Sem $\mathrm{Au}$

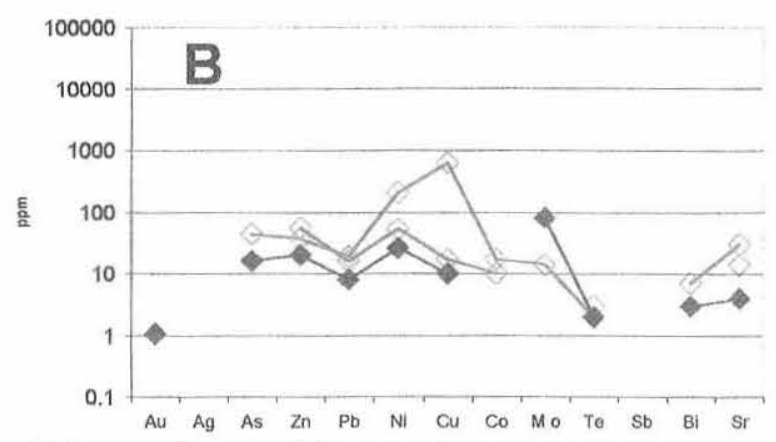

- Veio de quartzo-Baixo teor $\mathrm{Au} \uparrow$ Veio de quartzo-Sem Au

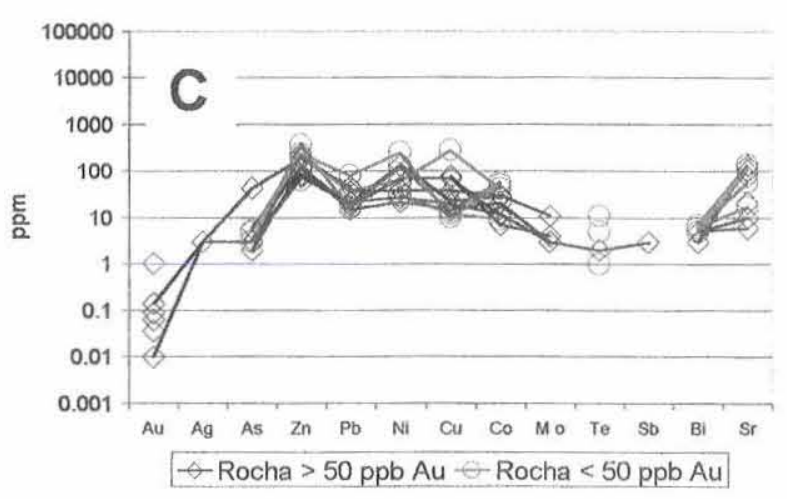

Fig.8: Características químicas das rochas e minérios da mina Schramm. (A) Teores dos veios siderítico-ankeríticos. Jumto ao Au (500-2300ppm) os veios carbonáticos têm altos teores de prata (150 a $300 \mathrm{ppm})$. arsênio $(0.15$ a $0.60 \%)$ e niquel $(0.01$ a $1.4 \%)$. Em menores proporções o minério tem $\mathrm{Zn}(250$ a $1600 \mathrm{ppm}), \mathrm{Pb}(100$ a $850 \mathrm{ppm})$ e Co $(40$ a $750 \mathrm{ppm})$. Os teores de $\mathrm{Sb}$, Te, Se. IV. Mo e Bi são muito baixos, próximos ou menores que $10 \mathrm{ppm}$. (B) Os veios de quarzzo sem Au têm teores mais elevados de As, Zn, Pb, Ni, Cu Te, Bi e Sr que aqueles com Au. (C) Nas rochas alteradas os teores de Au> $>50 \mathrm{ppb}$ não são acompanhados de teores mais elevados dos outros elementos de minério. 
Tabela 7: Mina Schramm - Teores das rochas e dos veios mineralizados em elementos traşos de tendências calcófila, siderófila e metais raros (para saber o tipo de amostra, consultar o Tabela 5, segunda coluna).

\begin{tabular}{|c|c|c|c|c|c|c|c|c|c|c|c|c|c|c|}
\hline Amostra & Au & $\mathrm{Au}$ & $\mathrm{Ag}$ & As & $\mathrm{Zn}$ & $\mathrm{Pb}$ & $\mathrm{Ni}$ & $\mathrm{Cu}$ & Co & Mo & Te & $\mathrm{Sb}$ & $\mathrm{Bi}$ & $\mathrm{Sr}$ \\
\hline & $(\mathrm{ppm})$ & (ppb) & $(\mathrm{ppm})$ & (ppm) & $(\mathrm{ppm})$ & $(\mathrm{ppm})$ & $(p p m)$ & $(\mathrm{ppm})$ & $(\mathrm{ppm})$ & $(\mathrm{ppm})$ & $(\mathrm{ppm})$ & $(\mathrm{ppm})$ & $(\mathrm{ppm})$ & $(\mathrm{ppm})$ \\
\hline \multicolumn{15}{|c|}{ Rochas encaixantes dos veios de quartzo e carbanato } \\
\hline SC-4I & $<0,01$ & $<5$ & $<1$ & 1 & 18 & 10 & 36 & 5 & 3 & 12 & $<1$ & $<3$ & $<1$ & 66 \\
\hline SC-39 & $<0,01$ & $<5$ & $<1$ & 1 & II & 11 & 45 & 5 & $<3$ & 15 & $<1$ & $<3$ & $<1$ & 9 \\
\hline SC.34 & $<0,01$ & 10 & $<1$ & 2 & 49 & 10 & 90 & 17 & 20 & 8 & $<1$ & 5 & $<1$ & 25 \\
\hline SC-33 & $<0,01$ & $<5$ & $<1$ & 4 & 11 & 10) & 38 & 3 & 7 & 12 & $<1$ & $<3$ & $<1$ & 14 \\
\hline SC-32 & $<0,01$ & 62 & $<1$ & 6 & 45 & 9 & 93 & 85 & 14 & 7 & $<1$ & $<3$ & $<1$ & 12 \\
\hline \multicolumn{15}{|c|}{ Rochas com altera cũes hipogênicas } \\
\hline SC-3IB & \begin{tabular}{|l|} 
n.d. \\
\end{tabular} & n.d. & n.d. & 3 & $3(x)$ & 16 & 126 & 14 & 58 & $<1$ & 5 & $<3$ & 6 & 17 \\
\hline $\mathrm{SC}-29 \mathrm{C}$ & n.d. & n.d. & n.d. & $<1$ & 63 & $<1$ & 30 & 12 & 9) & $<1$ & $<1$ & $<3$ & 5 & $I(x)$ \\
\hline SC-29A & nid. & n.d. & n.d. & 35 & 53 & 39 & 146 & 41 & 52 & $<1$ & 15 & $<3$ & 11 & 30 \\
\hline SC-28P & n.d. & n.d. & n.d. & 5 & 156 & 17 & 89 & 104 & 7 & $<1$ & 4 & $<3$ & 8 & 42 \\
\hline SC-28E & $<0,01$ & 140 & 3 & 43 & 188 & 45 & $<1$ & 78 & 7 & 4 & $<1$ & $<3$ & $<1$ & 21 \\
\hline$S C-24 A$ & $\langle 0,0|$ & $<5$ & 3 & 3 & 231 & 36 & 39 & 38 & 30 & 11 & $<1$ & $<3$ & 5 & 6 \\
\hline SC-22 & $<0,01$ & 62 & $<1$ & 3 & 86 & 22 & 27 & 19 & 12 & 3 & 2 & $<3$ & $<1$ & 78 \\
\hline $\mathrm{SC}-21$ & $<0,01$ & 88 & $<1$ & 2 & 122 & 15 & 22 & 15 & 21 & 3 & 2 & $<3$ & 3 & 134 \\
\hline SC-20 & nd. & n.d. & n.d. & 2 & +23 & 43 & 40 & 23 & 23 & $<1$ & 6 & $<3$ & 3 & 56 \\
\hline SC.19) & n.d. & nd. & nd. & $<1$ & 91 & 1 & 61 & 11 & 22 & $<1$ & 3 & $<3$ & 5 & 16 \\
\hline SC. 18 & n.d. & n.d. & n.d. & $<1$ & $2+1$ & 16 & 80 & 17 & 24 & $<1$ & 2 & $<3$ & 3 & 161 \\
\hline SC- 17 & n.d. & n.d. & n.d. & $<1$ & 385 & 19) & 39) & 33 & 25 & $<1$ & 5 & $<3$ & $<1$ & 48 \\
\hline SC.16 & 1.04 & n.d. & $<1$ & 3 & 75 & 20) & 1,36 & 23 & 28 & $<1$ & 2 & 3 & $<1$ & 106 \\
\hline $\mathrm{SC}-15$ & n.d. & n.d. & n.d. & $<1$ & 98 & 12 & 72 & 1.32 & 27 & $<1$ & 4 & $<3$ & 7 & 52 \\
\hline $\mathrm{SC}-14$ & n.d. & n.d. & n.d. & 5 & 237 & 81 & 249 & 10 & 51 & $<1$ & 1 & $<3$ & 7 & 137 \\
\hline$S C-13 B$ & n.d. & n.d. & n.d. & 5 & 203 & 38 & 59 & 278 & 41 & $<1$ & 11 & $<3$ & 6 & 58 \\
\hline $\mathrm{SC}-13 \mathrm{~A}$ & nd. & n.d. & n.d. & $<1$ & 146 & 42 & 25 & 38 & 10 & $<1$ & 3 & $<3$ & $<1$ & 556 \\
\hline SC-12 & n.d. & n.d. & n.d. & $<1$ & 164 & 19 & 195 & 2017 & 46 & $<1$ & 7 & $<3$ & 7 & 179 \\
\hline SC-11 & $<0,(0)$ & 36 & $<1$ & 6 & 118 & 18 & 70 & 68 & 11 & $<1$ & $<1$ & $<3$ & 5 & 10 \\
\hline SC-10 & \begin{tabular}{|l|} 
n.d. \\
\end{tabular} & n.d. & nd. & $<1$ & 109 & 51 & 11 & 10 & $<3$ & $<1$ & 2 & $<3$ & $<1$ & 163 \\
\hline SC-(1) & n.d. & n.d. & n.d. & $<1$ & 113 & 35 & 11 & 13 & $<3$ & $<1$ & 4 & $<3$ & 3 & 9 \\
\hline SC. 077 & $\langle(1,0)|$ & 31 & $<1$ & $<1$ & 36 & 15 & 15 & 17 & 4 & 7 & 3 & $<3$ & 3 & 25 \\
\hline $\mathrm{SC}-(12)$ & n.d. & n.d. & n.d. & 26 & 156 & 24 & 98 & $I(X)$ & (6i) & $<1$ & 29 & $<3$ & 7 & 6 \\
\hline$S C-01 A$ & n.d. & n.d. & n.d. & $<1$ & 123 & 17 & 50 & 4 & 7 & $<1$ & $<1$ & $<3$ & 5 & 12 \\
\hline \multicolumn{15}{|c|}{ Veios de quartzo } \\
\hline SC-28M & n.d. & nd. & n.d. & $<1$ & $<1$ & 20 & 37 & 13 & 3 & $<1$ & 2 & $<3$ & $<1$ & 4 \\
\hline SC-28L & n.d. & n.d. & n.d. & $<1$ & 32 & 10 & 39 & 15 & 1 & $<1$ & 1 & $<3$ & 2 & 21 \\
\hline SC.28K & 1.015 & nd. & $<1$ & 16 & 20 & 8 & 26 & 10 & $<3$ & 79 & 2 & $<3$ & 3 & 4 \\
\hline SC-28J & n.d. & nd. & n.d. & $<1$ & 55 & 16 & 53 & 17 & 10 & $<1$ & 3 & $<3$ & 7 & 30 \\
\hline$S C-25 B$ & n.d. & n.d. & n.d. & 67 & 71 & 54 & 144 & 1366 & 88 & $<1$ & 45 & $<3$ & 6 & 37 \\
\hline SC-25A & $\langle 0.01$ & 47 & $<1$ & 44 & 37 & 19) & 206 & 627 & 17 & 14 & 2 & $<3$ & $<1$ & 14 \\
\hline SC-23A & \begin{tabular}{|l|} 
n.d. \\
\end{tabular} & n.d. & $<1$ & $<1$ & + & 19 & $2 x$ & 14 & $<3$ & $<1$ & 2 & $<3$ & 3 & 7 \\
\hline \multicolumn{15}{|c|}{ Veio de carbonato (siderita + ankerita + dolomita) } \\
\hline \begin{tabular}{ll|} 
SC- 280 \\
\end{tabular} & 1415 & n.t. & 184 & \begin{tabular}{|l|}
$32(X)$ \\
\end{tabular} & 40 & 162 & 4186 & 106 & 52 & 13 & 1 & $<3$ & $<1$ & 2 \\
\hline SC-2XN & 2254 & nd. & 217 & $15 \times 9$ & 259 & 107 & 912 & 81 & 40 & 5 & $<1$ & $<3$ & $<1$ & 2 \\
\hline SC-28G & 2177 & n.t. & $2 \times 3$ & 6049 & 1624 & 860 & 13686 & 59 & 771 & 170 & 4 & 12 & $<1$ & 2 \\
\hline$S C-24 B$ & nd. & nd. & $<1$ & 2 & 404 & 39 & 27 & 18 & 7 & $<1$ & 4 & $<3$ & $<1$ & 31 \\
\hline$S C-23 B$ & n.d. & n.d. & $<1$ & $<1$ & 125 & 0 & 86 & 17 & 46 & $<1$ & $<1$ & $<3$ & 5 & 112 \\
\hline
\end{tabular}

sulfoarseneto de Ni-Fe-Co desconhecido e de covelita (Figs. 9 e $10 \mathrm{e}$ Tabela 8), cristalizados na ordem mostrada no Tabela 9.

O ouro foi a primeira fase metálica a cristalizar, seguido da galena (traços), da calcopirita (muito pouco), da arsenopirita (traços) e da esfalerita. O ouro ocorre livre $\mathrm{em}$ meio aos carbonatos (Fig. $10 \mathrm{C}$ ) e como inclusões nos sulfetos (Fig. 9 C, D, E c Fig. 10 A, B, E e F). Os sulfetos mais comuns são a gersdorfita, a millerita e a siegenitaviolarita (grupo da linaeita). A gersdorfita geralmente envolve a millerita que ocorre isolada (Fig. $9 \mathrm{C} \mathrm{e} \mathrm{D)} \mathrm{ou} \mathrm{como} \mathrm{exsolução} \mathrm{dentro}$ de uma variedade de siegenita rica em Fc, transicional para a violarita (Fig, 9 E e $10 \mathrm{~A}$ e B). Gersdorfita, siegenita e millerita têm inclusões de esfalerita (Fig. 9 C e E, Fig. 10 A, B c D), calcopirita (Fig. $9 \mathrm{Cc}$ E, Fig. $10 \mathrm{~A}$ ), galena c arsenopirita. Nas 23 secções polidas estudadas, somente um cristal de arsenopirita foi encontrado e analisado (Tabela 8).

O cálculo das fórmulas estruturais dos minerais metálicos da mina Schramm (Tabela 10) mostra que o ouro tem $27,5 \%$ de $\mathrm{Ag}$ e que a siegenita é uma variedade rica em $\mathrm{Fe}$, transicional para a violarita. $\mathrm{O}$ minério tem uma variedade de pirita níquel-cobaltífera e um sulfarseneto com fórmula $(\mathrm{Co}, \mathrm{Fe}, \mathrm{Ni})_{7.980} \mathrm{As}_{9.0 \times(x)} \mathrm{S}_{6.000}$ (Tabelas $8 \mathrm{e} 10$ e Fig. $10 \mathrm{E} \mathrm{e} \mathrm{F)} \mathrm{do} \mathrm{qual} \mathrm{não} \mathrm{foi} \mathrm{encontrada} \mathrm{referência} \mathrm{na} \mathrm{literatura.}$ Esse mineral tem propriedades óticas semelhantes às da gersdorfita, diferenciando-se apenas pela côr cinza-creme pouco mais acentuada. Engloba cristais de ouro e tem uma franja de gersdorfita (Fig. 10 E), da qual se separa por uma superfície na qual se cristalizaram calcopirita e millerita (Fig. 10 F).

A pirita euédrica, cristalizada tardiamente, tem composição química (Tabela 8) diferente da pirita que ocorre nos locais mineralizados, junto da gersdorfita, que é anédrica e intersticial, (Tabela $8 \mathrm{e} \mathrm{Fig.} 9$ C). A pirita anédrica tem níquel (teor médio de $0,73 \%$ ) e cobalto (teor médio de 1,18\%), apresenta birreflectância muito tênue c é mais clara que a pirita euédrica. A magnetita dos metajaspilitos é quimicamente pura, desprovida de quantidades significativas de qualquer elemento traço. A covelita, identificada em apenas duas amostras, é derivada da alteração da calcopirita, ocorrida no final do ciclo principal de alteração hipogênica. As amostras com covelita (fig. 11 A) foram coletadas $\mathrm{em}$ locais onde as encaixantes do veios carbonático estão oxidadas (oxidação pervasiva) e caulinizadas (Tabelas $3 \mathrm{e} 4$ ).

CONCLUSÕES A mina Schramm é constituida por veios maciços de siderita-ankerita e por veios de quartzo com aglomerados de carbonato e de cloritas. Praticamente todo o ouro da mina está contido nos veios maciços de siderita-ankerita, em locais de distribuição errática, onde os veios alargam-se formando bolsões alongados, verticalizados, com cerca de 1,5 m de diâmetro e 10-30 m de comprimento. Nesses locais os veios de carbonato têm teores de ouro entre 500 e 2300 ppm e os veios de quartzo têm menos de 1 ppm. Fora desses bolsões não há ouro nem nos veios carbonatados nem nos veios de quartzo.

Os veios são orientados $\mathrm{N} 75^{\circ}-85^{\circ} \mathrm{W}$ c estão $\mathrm{cm}$ fraturas tensionais

Tabela 9: Sucessão de cristalização dos minerais metálicos que cristalizaram junto ao ouro dentro dos veios carbonatados nos locais com altos teores de ouro da mina Schramm. ATENÇÃO: total de sulfetos é menor que $0.5 \%$ em volume da rocha.

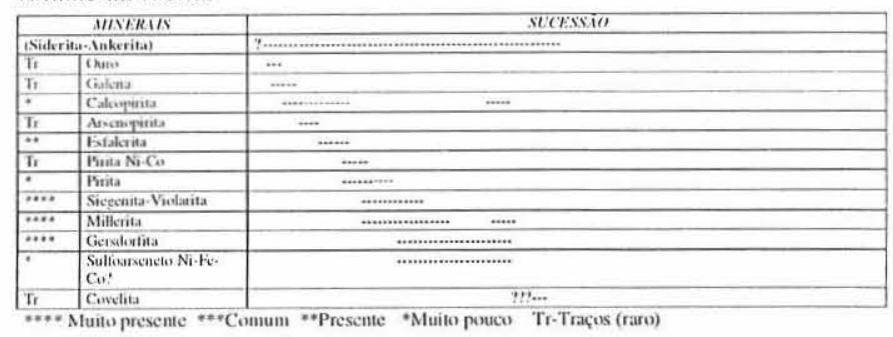


Tabela 8: Mina Schramm - Médias (em frente ao nome do mineral) e resumo estatístico dos resultados de análises de minerais feitas na microssonda eletrônica.

\begin{tabular}{|c|c|c|c|c|c|c|c|c|c|c|c|c|c|}
\hline \multicolumn{14}{|c|}{ Média das análises de ouro } \\
\hline & $\begin{array}{c}N^{N " D E} \\
\text { ANÁLISES } \\
\end{array}$ & $\begin{array}{l}\mathrm{Ni} \\
(\%)\end{array}$ & $\begin{array}{l}\text { Au } \\
\text { (\%) }\end{array}$ & $\begin{array}{l}\mathrm{Cu} \\
(\mathrm{z})\end{array}$ & $\begin{array}{l}\text { As } \\
(\%)\end{array}$ & $\begin{array}{c}\mathrm{PH} \\
(\%)\end{array}$ & $\begin{array}{c}S \\
(\%)\end{array}$ & $\begin{array}{l}\mathrm{Pd} \\
(\%)\end{array}$ & $\begin{array}{l}\mathrm{Ag} \\
(\%)\end{array}$ & $\begin{array}{l}\mathrm{Sb} \\
(\%)\end{array}$ & $\begin{array}{l}\text { Te } \\
\text { (\%) }\end{array}$ & $\begin{array}{l}\mathrm{Bi} \\
(\mathrm{zi})\end{array}$ & \\
\hline Ouro & 16 & & 88,32 & & & & 0.07 & $<0,01$ & 13.25 & & & & \\
\hline & & & 1,04 & & & & $\frac{0.04}{0.01}$ & & 0.82 & & & & \\
\hline $\begin{array}{l}\text { Menor } \\
\text { Maior }\end{array}$ & & $\frac{\langle 0.01}{0.69}$ & $\frac{86,(x)}{89.88}$ & $\frac{<0,01}{0,031}$ & $\begin{array}{c}<0,01 \\
0,39\end{array}$ & $\frac{<0.01}{<0.01}$ & $\frac{0.01}{0.14}$ & $\begin{array}{l}<\langle 0,01 \\
<(0)\end{array}$ & $\frac{12.36}{14.71}$ & $<0,01$ & $<0,01$ & $<0,01$ & \\
\hline \multicolumn{14}{|c|}{ MÉdia das análises dos sulfectos } \\
\hline MINERAL. & $\mathrm{N}^{\prime \prime D E}$ & $\mathrm{Fe}$ & $C_{0}$ & $\mathrm{Ni}$ & Au & $\mathrm{Cu}$ & $\mathrm{Zn}$ & As & $P_{1}$ & $\mathrm{~s}$ & Pd & $\mathrm{Ag}$ & \\
\hline & ANÁLISES & (\%) & (8) & (3) & (\%) & (8) & (\%) & (\%) & (\%) & (\%) & (\%) & (\%) & (7) \\
\hline Arschopinita & 1 & 34,39 & 0.06 & 0.09 & 0 & 0,04 & 0,3 & 46,68 & 0 & 18,74 & 0 & 0 & 0.01 \\
\hline Calcupirita & 10 & 29,95 & & & & 34,13 & & & & 34,55 & & & \\
\hline$s$ & & 0.11 & & & & 0,09 & & & & 0,10 & & & \\
\hline Menor & & 29,34 & $<0,01$ & $<0,01$ & $<0,01$ & 33,69 & $<0,01$ & $<0.01$ & $<0,01$ & 34,35 & $<0,01$ & $<0,01$ & $<0,01$ \\
\hline Maior & & 30.28 & 0,29 & 0,85 & 0,83 & 34,47 & 0,43 & 0.16 & 0.07 & 34,76 & 0,04 & 0.14 & 0,07 \\
\hline Essfalcrita & 11 & 1.21 & 0,08 & & & & 63,85 & & $<0,01$ & 33 & & 0,03 & 0,01 \\
\hline $\mathrm{s}$ & & 0.39 & 0.11 & & & & 0,19 & & & 0,11 & & 0,02 & 0,01 \\
\hline Menor & & 0,33 & 0,01 & $<0,01$ & $<0,01$ & $<0.01$ & 63,26 & $<0,01$ & $<0,01$ & 32,46 & $<0,01$ & $<0,01$ & $<0,01$ \\
\hline Maior & & 1.90 & 0,26 & 1,68 & $<0,01$ & $0,(09)$ & 64,23 & 0.87 & $<0,01$ & 33.30 & 0,05 & 0.08 & 0,05 \\
\hline Gersdorfita & 13 & 0.54 & 0.84 & 34,05 & & & & 43,95 & & 19,52 & & & 0,19 \\
\hline 5 & & $0.3 \mathrm{x}$ & 0,66 & 0,93 & & & & 0.51 & & 0,16 & & & 0.09 \\
\hline Menor & & 0.20 & 0,11 & 31,70 & $<0,01$ & $<0,01$ & $<0,01$ & 42,90 & $<0.01$ & 19,30 & $<0.01$ & $<0,01$ & 0,014 \\
\hline Maior & & 1.33 & 2,80 & 34,97 & 0,14 & 0,03 & 3,28 & 44.85 & 0.104 & 19,90 & \begin{tabular}{|l|l|}
0,03 & \\
\end{tabular} & \begin{tabular}{|l|}
0,06 \\
\end{tabular} & 0,33 \\
\hline $\begin{array}{l}\text { Sullirrscencto } \\
\text { Ni-Fe-Co? }\end{array}$ & 3 & 3.99 & 2.69 & 27.27 & & & & 50,69 & & 14,45 & & & 0.077 \\
\hline 5 & & 4.29 & 1.27 & 2,71 & & & & 3.71 & & 3,39 & & & 0,07 \\
\hline Menor & & 1.18 & 1.30 & 24.50 & $<0,01$ & $<0.01$ & $<0,01$ & 46.84 & $<0,01$ & 11.22 & $<0,01$ & $<0,01$ & 0,05 \\
\hline Mtaior & & 8.93 & 3.81 & 29,92 & 0.10 & 0.03 & 0,05 & 54,26 & 0.02 & 17,97 & \begin{tabular}{|l|}
0,02 \\
\end{tabular} & \begin{tabular}{|l|}
0,09 \\
\end{tabular} & 0,08 \\
\hline Milleriia & 9 & 1.52 & 1.00 & 61.34 & & & & 0.22 & & 35.46 & & & \\
\hline 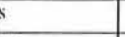 & & 1.19 & 1,06 & 2,67 & & & & 0.19 & & 0,80 & & & \\
\hline Menor & & 0.62 & $0.2 \mathrm{x}$ & 54.47 & $<0.01$ & $<0,01$ & $<0,01$ & 0.022 & $<0,01$ & 34,61 & $<0,01$ & $<0,01$ & $<0,01$ \\
\hline Maior & & 4.46 & 3,65 & 62,91 & 0.25 & 0,02 & 0.10 & 0.61 & 0,14 & 37.37 & \begin{tabular}{|l|}
0.02 \\
\end{tabular} & 0,09 & 0,03 \\
\hline Pinita cusdrica & 15 & 46,35 & & & & & & & & 52,92 & & & \\
\hline$s$ & & 0,22 & & & & & & & & 0,18 & & & \\
\hline Nenor & & $45.8-4$ & $<0,01$ & $<0,01$ & $<0.01$ & $<0.01$ & $<0,01$ & $<0,01$ & $<0,01$ & 52.58 & $<0,01$ & $<0,01$ & $<0,01$ \\
\hline Maior & & 46,714 & 0,15 & 0,70 & 0,18 & 0.81 & 1,29 & 0,49 & 0.12 & \begin{tabular}{|l|}
53,66 \\
\end{tabular} & \begin{tabular}{|l|l|}
0,08 \\
\end{tabular} & \begin{tabular}{|l|l|}
0,06 \\
\end{tabular} & 0.12 \\
\hline $\begin{array}{l}\text { Piritia nifucl- } \\
\text { cobalufifera }\end{array}$ & 3 & 45.35 & 1.18 & 0.73 & & 0.02 & & & & 52,72 & & & \\
\hline 5 & & 0.14 & 0,18 & 0,08 & & 0.02 & & & & 0.09 & & & \\
\hline Menor & & 45.19 & 1.01 & 0.64 & $<0,01$ & 0.01 & $<0.01$ & $<0,01$ & $<0,01$ & 52,61 & $<0,01$ & $<0,01$ & $<0,01$ \\
\hline Maior & & 45,46 & 1.36 & 0,81 & 0.17 & 0,03 & 0,07 & 0,14 & 0,11 & 52,78 & \begin{tabular}{|l|l}
0,02 \\
\end{tabular} & \begin{tabular}{|l|l|}
0,05 \\
\end{tabular} & 0,03 \\
\hline $\begin{array}{l}\text { Siegenit:/Vio } \\
\text {-larilai }\end{array}$ & 8 & 10.04 & 11,02 & 35,49 & & & & 0,37 & & 41,75 & & & \\
\hline & & 2,00 & 1.51 & 0,41 & & & & 0,32 & & 0,79 & & & \\
\hline Menor & & 6.09 & 8,31 & 34,98 & $<0,01$ & $<0.01$ & $<0,01$ & 0,05 & $<0.01$ & 39.88 & $<0,01$ & $<0,01$ & $<0,01$ \\
\hline Maior & & 12,80 & 12.80 & 36.17 & 0.12 & 0,07 & 0,10 & 0,87 & 0.06 & 42,42 & 0.04 & 0,03 & 0.03 \\
\hline \multicolumn{14}{|c|}{ MÉdia das antilises } \\
\hline & $\begin{array}{l}\text { N"DDE } \\
\text { ANÁLISE }\end{array}$ & $\mathrm{Al2O3}$ & TiO2 & $F_{i}$ & $\mathrm{NiO}$ & $\mathrm{C}_{2} \mathrm{O} 3$ & $\mathrm{MnO}$ & $\mathrm{Fe}_{2} \mathrm{C}$ & & & & & \\
\hline Magnetita & 10 & $\frac{1.17}{0.15}$ & & $\begin{array}{l}30,67 \\
30,67\end{array}$ & & & & $\frac{1717}{67.76}$ & & & & & \\
\hline & & 0.11 & & 0.19 & & & & 0.46 & & & & & \\
\hline & & & & & $<0.01$ & $<0.6$ & & & & & & & \\
\hline Maior & & 0.42 & 0.10 & 30.95 & $0,0 \mathrm{x}$ & 0.12 & 0.07 & $6 \times 2.28$ & & & & & \\
\hline
\end{tabular}

de uma zona de cisalhamento NS, verticalizada. A ausência de deformação nos veios e nas encaixantes com alterações hipogênicas indica que não houve metamorfismo ou tectonismo importantes após a fase de mineralização.

As paragêneses de alteração hipogênicas das rochas encaixantes dos veio mineralizados são volumetricamente dominadas pela carbonatação (siderita + ankerita). A paragênese dominante, constituida por sericita+clorita+carbonato+quartzo, caracteriza uma alteração hipogênica principal de baixa temperatura. Uma segunda paragênese, volumetricamente limitada, constituida por óxido de ferro (pervasivo) e por caulim, caracteriza uma fase final de alteração hipogênica, de menor temperatura que a fase principal.

A carbonatação e a cloritização são as alterações hipogênicas dominantes na mina Schramm. Há um aumento contínuo de $\mathrm{FeO} *+\mathrm{MgO}+\mathrm{MnO}$ das rochas desde as rochas inalteradas (granitoides ou granulitos) até os veios maciços de carbonato.

Os teores normalizados dos veios de siderita-ankerita em elementos litófilos e incompatíveis praticamente não mudam quando o veio é estéril ou é mineralizado. Esses veios mostram-se, em relação aos chondritos, com anomalias positivas fortes em Rb, Ce e Nd e negativa de $\mathrm{Ba}$ e de $\mathrm{P}$. Em relação ao MORB têm anomalias positivas fortes de $\mathrm{Rb}$ e Ce e negativas de $\mathrm{K}, \mathrm{O}, \mathrm{Ba}, \mathrm{P}_{2} \mathrm{O}_{5}, \mathrm{Zr}$, $\mathrm{Sm}$ e TiO,

Nos bolsões de minério os veios càrbonáticos têm teores de ouro entre 500 e 2300 ppm e os veios de quartzo têm até 1 ppm. Fora das áreas de bolsões não há ouro. Junto ao ouro, também concentram-se, com altos teores, a prata (150 a 300 ppm), o arsênio $(0,15$ a $0,60 \%)$ e o níquel $(0,01$ a $1,4 \%)$. Em menores proporções o minério tem $\mathrm{Zn}$ (250 a 1600 ppm), Pb (100 a 850 ppm) e Co (40 a 750 ppm). Os teores de $\mathrm{Sb}$, Te, Se, W, Mo e Bi são muito baixos, próximos ou menores que $10 \mathrm{ppm}$.

Os veios de quartzo nos bolsões mineralizados têm teores de ouro de até 1 ppm e de $\mathrm{As}, \mathrm{Zn}, \mathrm{Pb}, \mathrm{Ni}, \mathrm{Cu}, \mathrm{Co}, \mathrm{Mo}$, Te, e Bi entre 1 e 50 ppm. Fora das regiões mineralizadas os teores de Au são menores que $50 \mathrm{ppb}$ e os teores dos outros elementos são maiores que os da zona mineralizada, variando entre 10 e $900 \mathrm{ppm}$. Raramente as rochas alteradas têm ouro e a presença deste em teores acima de $50 \mathrm{ppb}$ não traz. um aumento significativo nos teores dos outros elementos, cujos teores variam entre 1 e $200 \mathrm{ppm}$.

Nos bolsões com altos teores de ouro, o total de sulfetos é menor que $0,5 \% \mathrm{em}$ volume, e restringe-se aos veios de siderita-ankerita. A paragênese sulfetada é composta essencialmente por sulfetos de $\mathrm{Ni}$ e As secundados pelos de $\mathrm{Co}, \mathrm{Zn}$ e Cu. O ouro tem $27,5 \%$ de $\mathrm{Ag}$ e é acompanhado por galena, calcopirita, arsenopirita (muito rara), esfalerita, pirita níquel-cobaltífera, pirita, siegenita-violarita, millerita, gersdorfita, um sulfoarseneto de $\mathrm{Ni}$-Fe-Co desconhecido, com fórmula $(\mathrm{Co}, \mathrm{Fc}, \mathrm{Ni})_{7.980} \mathrm{As}_{9.000} \mathrm{~S}_{6.000}$, e de covelita. 
Tabela 10: Fórmulas dos minerais metálicos do minério da mina de ouro Schramm analisados na microssonda

\begin{tabular}{|c|c|c|c|}
\hline MINERAL & $\begin{array}{l}\text { NÚMERO DE MOLES ANALISADOS } \\
\text { (Nutmero inteiro de } S \text { in O) }\end{array}$ & FORMULA ANALISADA & FÓRMULA TEÓRICA \\
\hline Arsenopiritia & 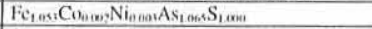 & 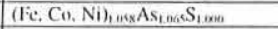 & FeAsS \\
\hline Calcopirita & 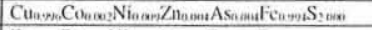 & 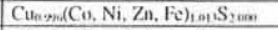 & CuFes, \\
\hline Estalcrita & 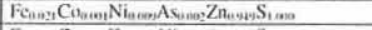 & (Zn. Fe, Co, Ni. Ashoms S S & $\mathrm{ZnS}$ \\
\hline Gersulerfitit & 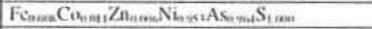 & 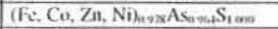 & NiAsS \\
\hline $\begin{array}{l}\text { Sullarsencto de } \\
\mathrm{Co}_{\mathrm{t}-\mathrm{Fi}-\mathrm{Ni}}\end{array}$ & 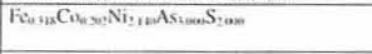 & 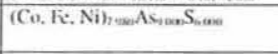 & Mineral desconhecido (?) \\
\hline Millerita & 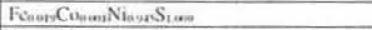 & (Ni, Fi: Cohns $S_{1} \ldots \ldots$ & $\mathrm{NiS}$ \\
\hline $\begin{array}{l}\text { Siegenita-Viola- } \\
\text { rita }\end{array}$ & 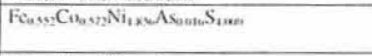 & 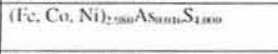 & $\left(\mathrm{Co}, \mathrm{Ni}_{1} \mathrm{~S}_{4}-\mathrm{Ni}_{2} \mathrm{FeS}_{4}\right.$ \\
\hline Pirita cuédrica & 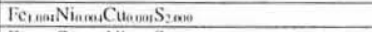 & (Fe. NI. Cu $)_{1, a m S} S_{2000}$ & $\mathrm{FeS}$, \\
\hline $\begin{array}{l}\text { Pirita niquel- } \\
\text { cobaltificra }\end{array}$ & 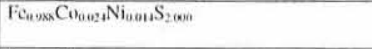 & $(\mathrm{Fe}, \mathrm{Co}, \mathrm{Ni})_{1,26} \mathrm{~S}_{21000}$ & $(\mathrm{Fc}, \mathrm{Co}, \mathrm{Ni}) \mathrm{S}_{2}$ \\
\hline Magnelita & 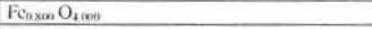 & $\mathrm{Fer}_{\mathrm{naO}} \mathrm{O}_{4 \times \mathrm{e}}$ & $\mathrm{Fin}_{1} \mathrm{O}_{4}$ \\
\hline Ouro & Atha+ลA & Ath7s Apars & $\mathrm{Au}$. a $(\mathrm{Ag}, \mathrm{Pl}, \mathrm{Pd}, \mathrm{Cu}, \mathrm{Te})_{\mathrm{s}}$ \\
\hline
\end{tabular}
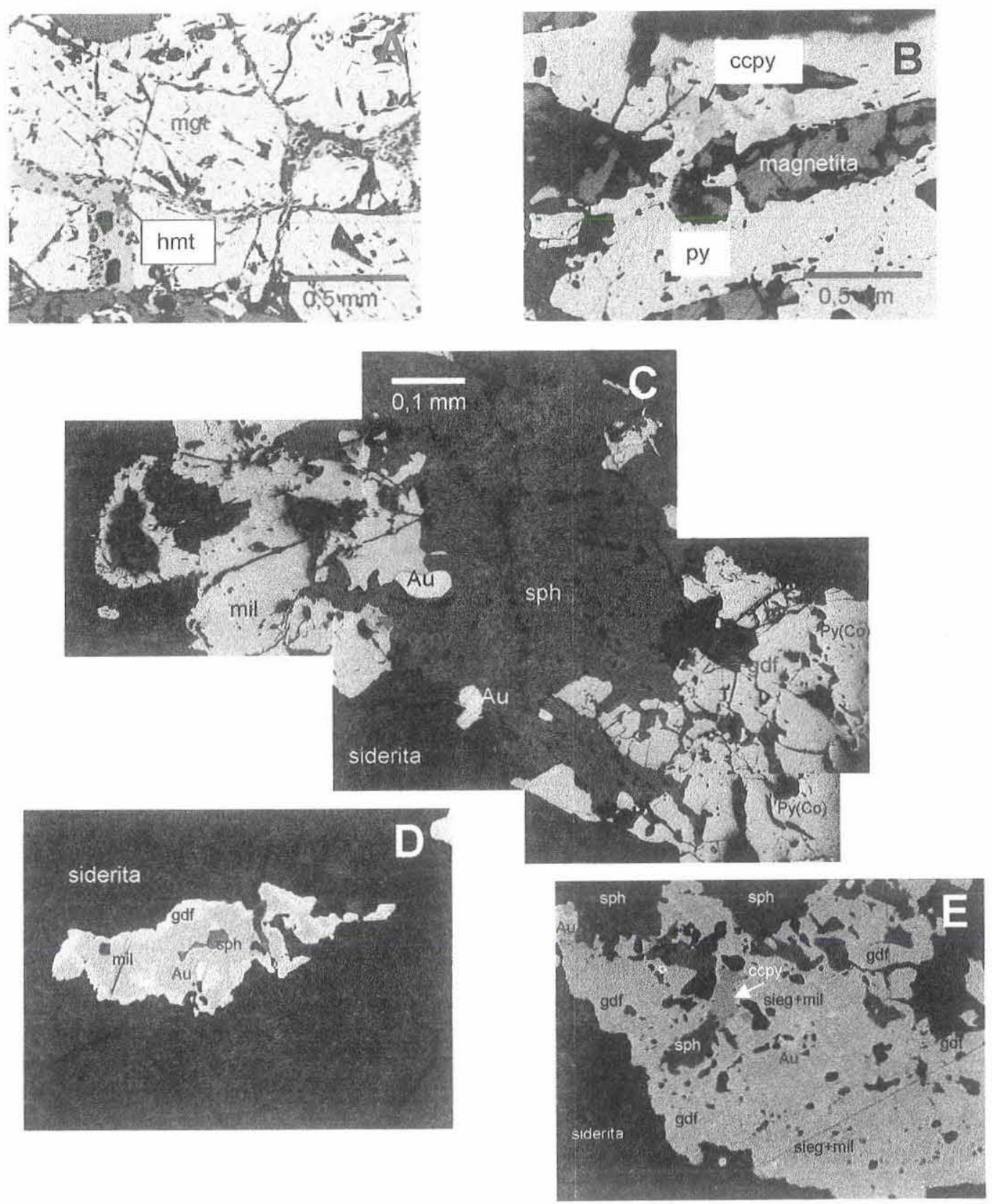

Fig. 9: Imagens de seções polidas de rochas e do minério da mina Schramm. (A) Magnetita e hematita dos metajaspilitos (luz azul, nicóis //). (B) Pirita e calcopirita imtersticiais na magnetita dos metajaspilitos (luz amarela, nicois //). (C) Associação de sulfetos típica dos locais com altos teores de Au: gersdorfita que envolve millerita, calcopirita, ouro, esfalerita e pirita (1ariedade níquel-cobaltifera) (luz amarela, nicois //). (D) Gersdorfita englobando millerita, ouro e esfalerita (luz amarela, nicois //). (E) Associașão complexa de gersdorfita, siegenita com exsoluşão de millerita, esfalerita, ouro e calcopirita (luz amarela,

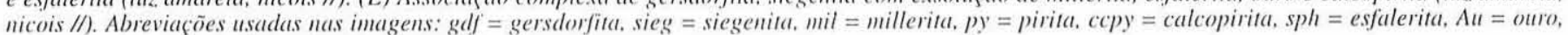
$m g t=$ magnetita. hmt $=$ hematita e $\mathrm{cvt}=$ covelita. 

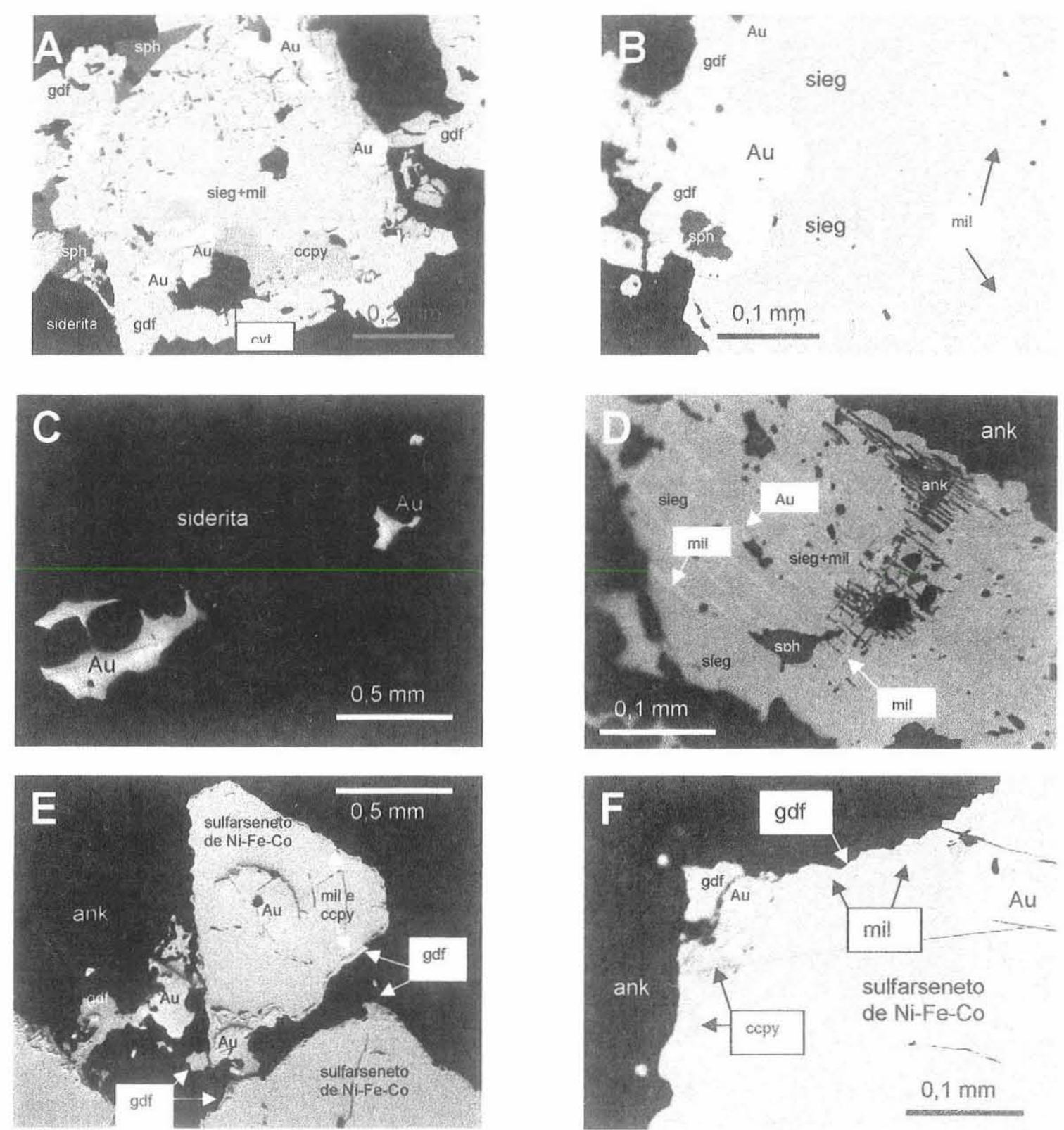

Fig. 10. Imagens de seçies poludas do minério da mina Schramm. (A) Associaç̃öo de gersdorfita, ouro, calcopirita, esfalerita e siegenita com exsolução de millerita. A covelita é produto da transformașōo tardia da calcopirita (luz amarela, nicóis /I). (B) Detallhe da imagem A, mostrando as lamelas de millerita exsolvidas na siegenita (luz amarela, nicóis //). (C) Ouro livre dentro da siderita (luz. amarela, nicóis //). (D) Siegenita com exsolução de millerita e inclusões de esfalerita. Notar resíduos näo substituidos de ankerita dentro da siegenita-millerita (luz amarela, nicóis //). (E) Sulfarseneto de Ni-Fe-Co, com fórmula (Co.

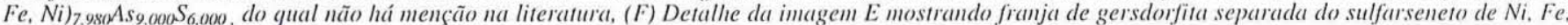
Co por uma superfície na qual se cristalizaran calcopirita e millerita. Mesmas abreviașöes da figura 9.

\section{Referências}

Babinsky M., Chemale Jr. F., Van Schmus W.R., Hartmann L.A.. da Silva L.C. 1997. U-P'b and $\mathrm{Sm}-\mathrm{Nd}$ geochronology of the neoproterozoic granitic-gneissic don Feliciano Belt. southern Brazil. Jour. South Amer: Earth Sci. 3-4:263-274.

Basei M.A. 1985. O Cinturão Don Feliciano em Santa Catarina. Instituto de Geociências. Universidade de São Paulo, Tese de Doutoramento, 193 p.

Biondi J.C., Schicker, G. e Bugalho, A. 1992. Processos mineralizadores em bacias tardiorogênicas: 1 - Influência das estruturas rígidas na geração dos depósitos da Minepar e do Ribeirão da Prata, Grupo Itajaí (SC). Rev. Brasil. Geociências, 22(3):275-288,

Pearce J.A. 1983. Role of the subcontinental lithosphere in magma genesis at active continental margins. In: "Continental Basalts and Mantle Xenoliths", C.J. Hakesworth e M.J. Norry (ed.), Shiva, Nantwich, 230-249
Rostirolla S.P. 1991. Tectônica e sedimentação da Bacia do Itajai. Departamento de Geociéncias, Universidade Federal de Ouro Preto. Tese de Mestrado. I3I p.

Thompson R.M. 1982. British Tertiary volcanic province. Scont. Jour: Geol. 18:49-107. 